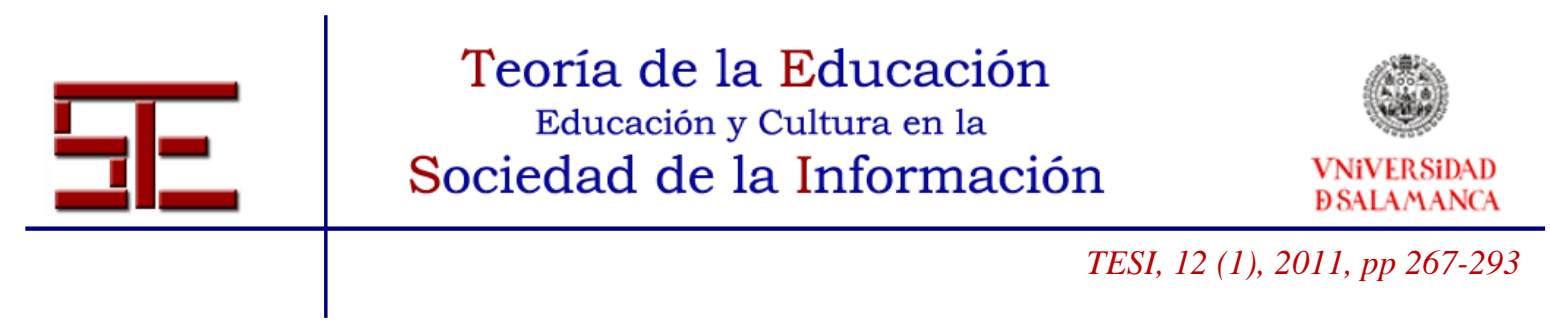

\title{
EL DOCENTE ANTE LAS LICENCIAS CREATIVE COMMONS: IMPLICACIONES EDUCATIVAS EN LA ESCUELA 2.0
}

Resumen: Actualmente vivimos en una etapa de cambios constantes en el mundo de la cultura y la educación. En las últimas décadas estamos presenciando una evolución hacia una sociedad del conocimiento donde es clave la expansión y uso crítico de las Tecnologías de la Información y la Comunicación (TIC) a todos los ámbitos de la vida. El paradigma tecnológico actual produce un cambio sustancial en el perfil profesional docente, y son fundamentales las habilidades y conocimientos que los profesores necesitan para contribuir en la escuela a construir en sus alumnos una competencia digital capaz de afrontar el reto de una sociedad en red y en permanente cambio social y tecnológico. En este contexto, los docentes deben conocer las implicaciones tecnológicas y educativas de las licencias Creative Commons, como una oportunidad para promover la competencia digital en la escuela 2.0.

Palabras clave: profesorado; competencia digital; TIC; Creative Commons.

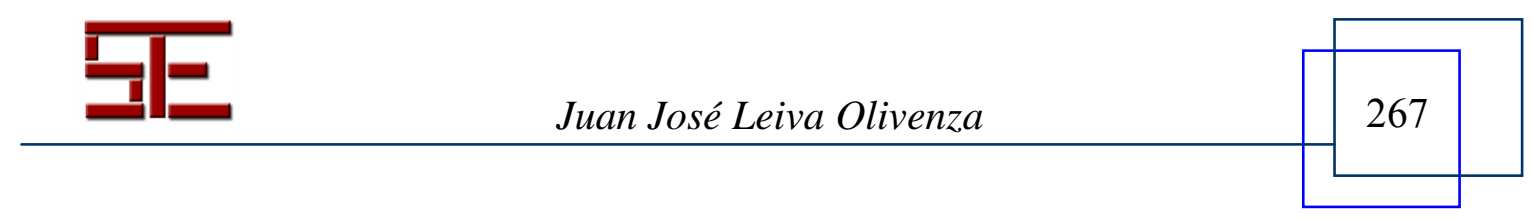




\title{
THE TEACHER TO THE CREATIVE COMMONS LICENSE: EDUCATIONAL IMPLICATIONS IN SCHOOL 2.0
}

\begin{abstract}
We currently live in an era of constant changes in the world of culture and education. In recent decades we are witnessing an evolution towards a knowledge society where the expansion is key and critical use of Information Technologies and Communication Technologies (ICTs) to all areas of life. The current technological paradigm substantial change in the teacher professional profile and are essential skills and knowledge that teachers need to help school students to build digital competence capable of addressing the challenge of a networked society and ongoing social and technological change. In this context, teachers must understand the technological and educational implications of the Creative Commons licenses as an opportunity to promote digital literacy in school 2.0.
\end{abstract}

Key words: teachers; digital competence; ICT, Creative Commons.

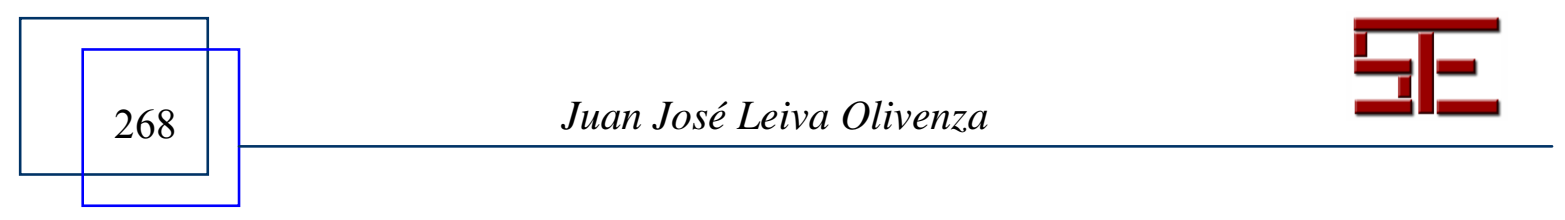




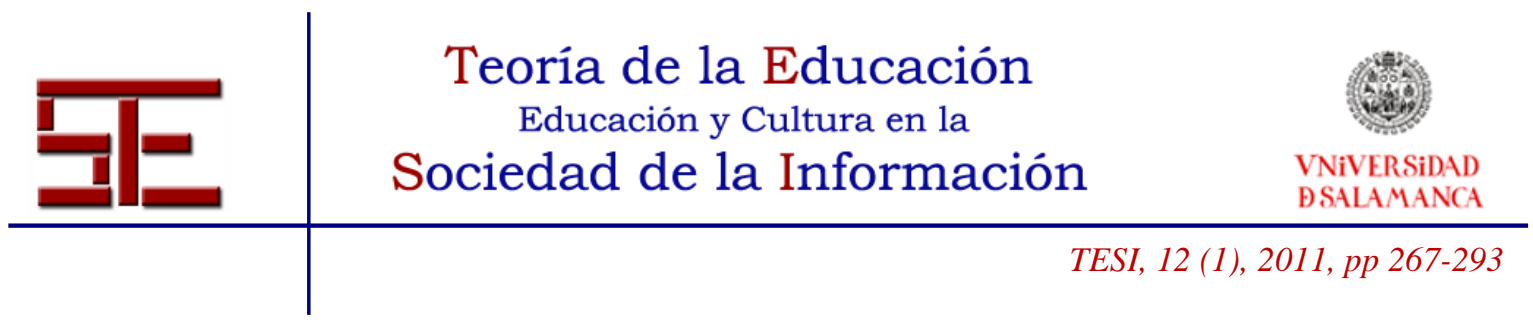

\section{EL DOCENTE ANTE LAS LICENCIAS CREATIVE COMMONS: IMPLICACIONES EDUCATIVAS EN LA ESCUELA 2.0.}

Fecha de recepción: 21/09/2010; fecha de aceptación: 22/01/2011; fecha de publicación: 31/03/2011

Juan José Leiva Olivenza
juanleiva@uma.es
Universidad de Málaga

\section{INTRODUCCIÓN}

Cada vez cobran mayor importancia las nuevas tecnologías en nuestra sociedad, tanto en escuelas como en comercios, viviendas, universidades, administraciones públicas, empresas, oficinas, etc. Nos encontramos en la sociedad del conocimiento, de las redes sociales y de las TIC. Por ello, los países de la Unión Europea, y entre ellos España, están decididos a impulsar la sociedad de la información sobre la base de que es necesario educar de manera crítica y efectiva en y con las TIC. Así pues, en el año 2009 el gobierno español ha decidido implantar el proyecto Escuela 2.0, para que en el curso escolar 2009/2010 los alumnos de tercer ciclo de Educación Primaria $\left(5^{\circ}\right.$ y $\left.6^{\circ}\right)$ hagan uso de las nuevas tecnologías en el aula, dotando a cada alumno de un ordenador portátil. De manera más precisa, el Ministerio de Educación lo planteaba en los siguientes términos:

Esta medida permitirá adaptar al siglo XXI los procesos de enseñanza y aprendizaje, dotando a nuestros alumnos de conocimientos y herramientas claves para su desarrollo personal y profesional... Se dotará a las aulas de pizarras digitales y conexión inalámbrica a Internet y cada alumno tendrá su propio ordenador personal, que usará como herramienta de trabajo en clase y en casa. Los profesores recibirán la formación adicional necesaria para adaptarse al ritmo que marcan las nuevas tecnologías... Siendo beneficiarios, los estudiantes de entre quinto de primaria y segundo de la ESO., es decir, de entre 10 y 13 años, y los profesores de primaria y secundaria. En el curso escolar 2009/2010, se dotará de un portátil a 400.000 alumnos y 20.000 profesores, y se digitalizarán 14.400 aulas.

En cierto modo, analizando el proyecto Escuela 2.0, podemos afirmar que para nuestro sistema educativo el hecho de dotarse de toda esa infraestructura tecnológica es una verdadera transformación, pero lo importante de esta propuesta radica precisamente en la traducción pedagógica y práctica de esta iniciativa. Es decir, ¿son tan importantes las TIC en educación? ¿Está el profesorado preparado para educar con y en las TIC? ¿Qué tipo de software se va a emplear en los centros educativos? Los profesores van a ser,

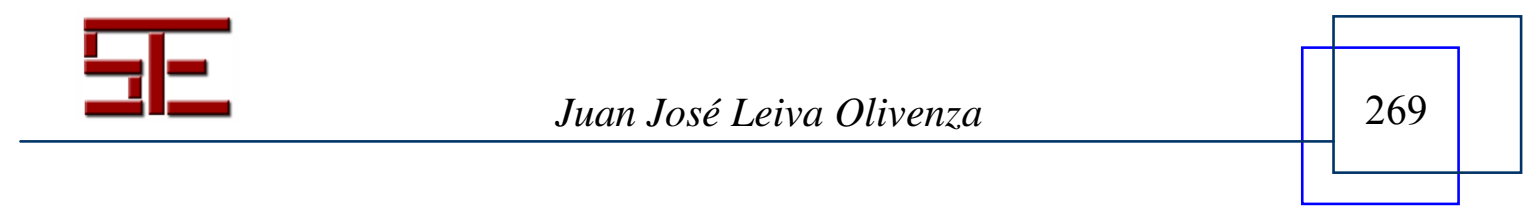




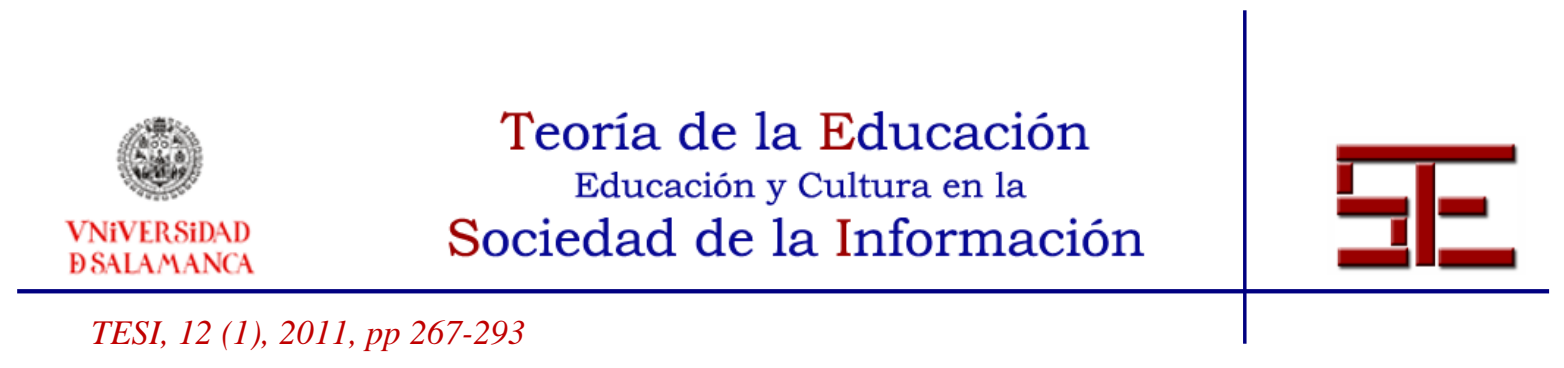

¿consumidores o creadores de software? Indudablemente las TIC han llegado a ser uno de los pilares básicos de la sociedad y hoy en día es necesario proporcionar al ciudadano del futuro una educación que tenga en cuenta esta realidad presente. Las posibilidades educativas de las TIC han de ser consideradas en dos aspectos: conocimiento y uso.

Por una parte, hacemos referencia al conocimiento informático, y es que esta consideración es consecuencia directa de la cultura globalizada de la sociedad actual. No se puede entender el mundo (educativo, profesional, laboral...) de hoy sin un mínimo de conocimiento informático. Por esta razón, hay que intentar participar en la generación y construcción de esta nueva cultura tecnológica. Desde luego eso implica un cambio de mentalidad de todos los agentes educativos, y supone contemplar las TIC como herramientas fundamentales en todos los niveles de la enseñanza (obligatoria y no obligatoria) y para lograr una formación a lo largo de toda la vida (aprendizaje permanente). Por otra parte, el segundo aspecto está relacionado con el primero y hace referencia a la parte técnico-práctica de la educación con nuevas tecnologías, es decir, al uso que damos a las TIC en el contexto educativo. En este punto, se deben utilizar para aprender a enseñar, y aprender a aprender. Además todas las áreas curriculares, sin excepción, se pueden enriquecer con esta tecnología y facilitar el proceso de enseñanzaaprendizaje de los alumnos/as, haciendo más dinámicas y motivadoras las clases.

No es fácil la enseñanza de las TIC, ya que es algo relativamente novedoso en el mundo de la escuela su incorporación plena. Tampoco se puede pretender que con esta medida se resuelvan todos los problemas existentes (fracaso escolar, bajo nivel de competencia curricular, desmotivación del alumnado, etc.), pero es necesario tratar de desarrollar métodos didácticos que relacionen la transmisión reflexiva de la información con el conocimiento académico curricular de manera relevante y funcional, y, sobre todo, aplicar la máxima de que los instrumentos virtuales de aprendizaje deben ser construidos y reconstruidos tanto por el docente como por el alumnado. En este sentido, son muchas las voces que insisten en la idea de que es fundamental que el profesorado se sensibilice y tenga motivación para formarse en TIC, porque no se puede enseñar algo cuando no se conoce y si los profesores no tienen la formación adecuada el plan Escuela 2.0 tiene pocas perspectivas de éxito (Peláez, 2009). De hecho, son necesarios programas de formación específicos en las nuevas tecnologías dirigidos al colectivo de profesores, para solventar las carencias de formación existentes. Zabalza (2006) plantea que en la docencia, como en cualquier otra profesión, subyace la idea del tifelong learning", esto es, la necesidad imperiosa de actualizarse permanentemente para estar en condiciones de dar una respuesta adecuada a las demandas del ejercicio profesional.

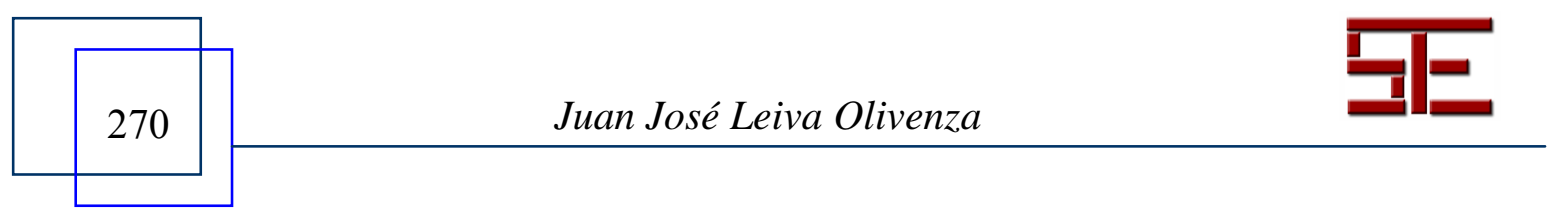




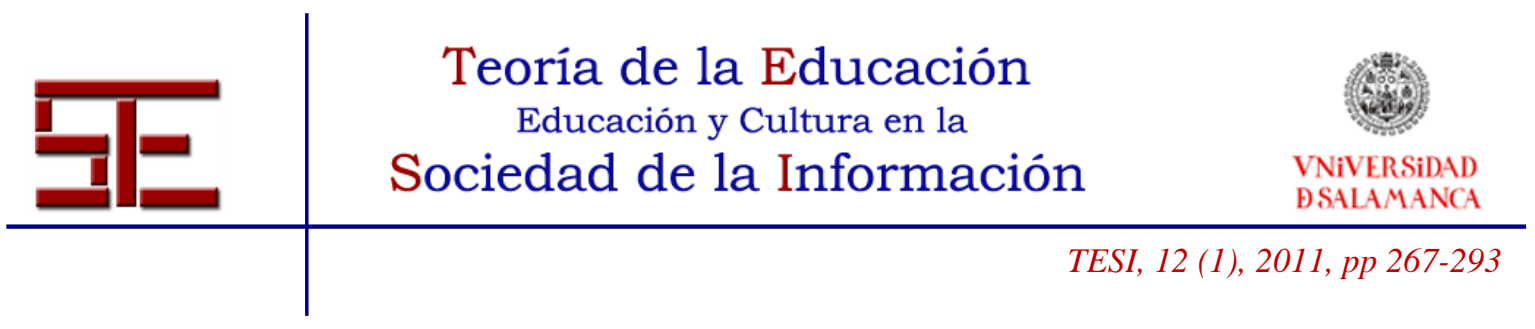

Esto quiere decir que los buenos profesionales de la educación se reciclan, se adaptan a los nuevos tiempos dominados por las redes sociales, actualizan su formación tecnológica, para poder realizar correctamente su trabajo y ser competentes en lo que hacen, que es enseñar a aprender. Y es aquí donde tiene pleno sentido la reflexión sobre la necesidad de que el docente no sea consumidor pasivo de programas y contenidos didácticos virtuales, sino que es clave que sea creador y productor de material multimedia y virtual interactivo. En este punto, la licencia Creative Commons $(\mathrm{CC}$, en adelante), o mejor dicho, las licencias CC tienen una gran importancia para el docente entendido como productor y consumidor de materiales de contenidos y recursos multimedia en el marco de la denominada Escuela 2.0.

\section{2. ¿QUÉ SON LAS LICENCIAS CREATIVE COMMONS?}

Cuando en 1971, Richard Stallman, un brillante estudiante de primero de Física de la Universidad de Harvard, se incorpora como programador al célebre Laboratorio de Inteligencia Artificial (IA Lab) del MIT, lo que encuentra allí es una comunidad de aprendizaje de investigadores y desarrolladores de software que comparten el código de todos sus descubrimientos informáticos. De esta forma todos los demás miembros del grupo y el resto de instituciones de investigación informática con los que estaban conectados podían beneficiarse de dicho código, adecuándolo a sus necesidades $\mathrm{y}$, sobre todo, mejorándolo y redistribuyéndolo para utilidad de la comunidad científica. Se puede decir que estamos ante el germen de todo lo que después se ha denominado corriente de software libre y de democratización informática en la actual sociedad del conocimiento (Cabello, 2006). Durante mucho tiempo estaba algo mal visto compartir información y programas, y el hecho de practicar ciertas dosis de egoísmo intelectual en materia de intercambio de programas informáticos era algo común. Esto lo reflejó muy bien en los años ochenta Levy (1984), cuando de manera paralela al desarrollo incipiente de Internet y al extraordinario desarrollo informático y tecnológico, emerge con fuerza un nutrido grupo de jóvenes hackers, en su mayoría estudiantes universitarios, que tenían como uno de sus objetivos el compartir, intercambiar y liberalizar aplicaciones y programas informáticos, lo cual fue una auténtica revolución cultural y un quebradero de cabeza para las empresas del sector.

A comienzos de la década de los ochenta Stallman desarrolla el proyecto GNU, nombre del sistema operativo que se propone comenzar a construir con el apoyo de cuantos programadores se sumen a él. Estamos haciendo referencia al nacimiento del movimiento social y cultural de software libre. De hecho, en el año 1985 publica el

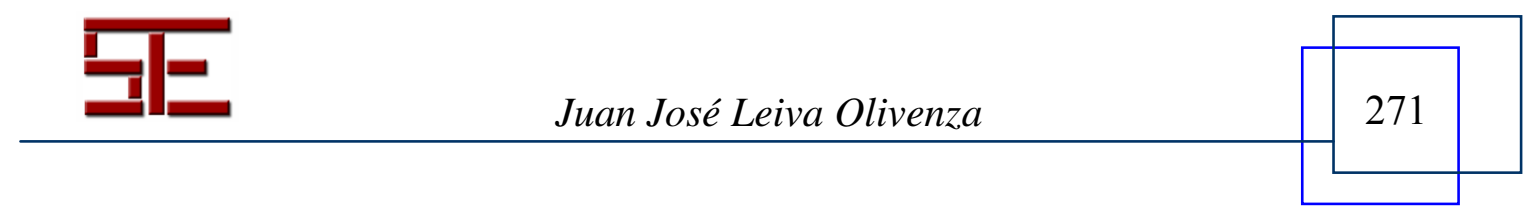




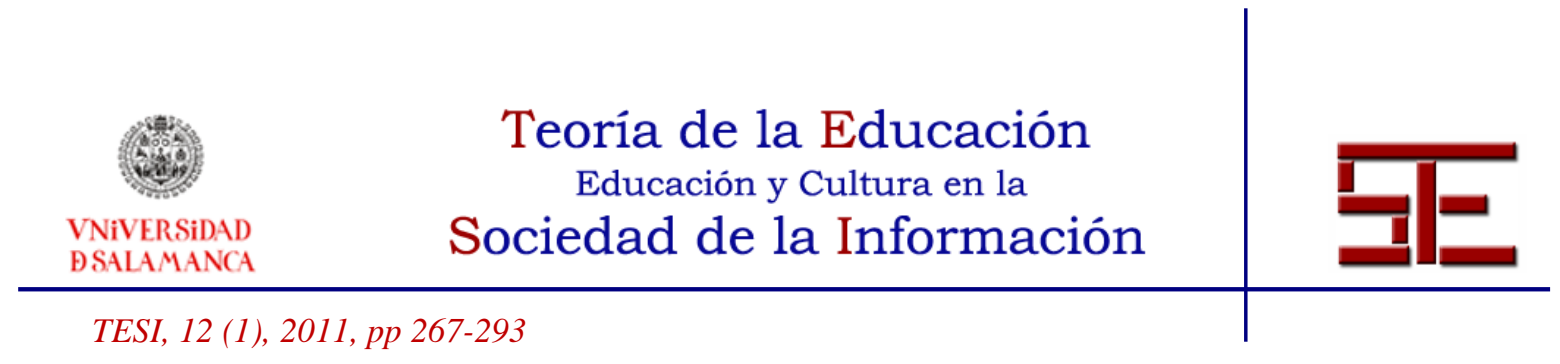

Manifiesto de GNU, donde expresa públicamente todas las motivaciones y argumentos debatidos hasta ese momento y expone los aspectos técnicos y éticos que implica dicho proyecto. Ese mismo año, crea la Free Software Foundation (FSF), una entidad no lucrativa que nace con dos objetivos fundamentales. Por un lado, recabar fondos (entre ellos, hay que subrayar los derivados de la propia venta de recopilaciones de software libre en formato CD-ROM) para contratar a programadores que escriban software en el marco del proyecto GNU; y proporcionar seguridad jurídica que, de alguna manera, no implique impedimentos o problemas legales con la legislación sobre propiedad intelectual (el copyright) para que el movimiento de software libre disponga de garantías legales de que todo su trabajo permanecerá siempre libre.

\begin{abstract}
De modo que deberías ser libre de redistribuir copias con o sin modificaciones, de forma gratuita o cobrando por su distribución, a cualquiera y en cualquier lugar. [...] Asimismo, deberías ser libre para introducir modificaciones y utilizarlas de forma privada, ya sea en tu trabajo o en tu tiempo libre, sin siquiera tener que mencionar su existencia. [...] La libertad para utilizar un programa significa que cualquier individuo u organización podrán ejecutarlo desde cualquier sistema informático, con cualquier fin y sin la obligación de comunicárselo subsiguientemente ni al desarrollador ni a ninguna entidad en concreto. (Stallman, 2004, 59).
\end{abstract}

Llegados a este punto, cabe señalar que Creative Commons es una organización sin ánimo de lucro creada por los profesores Lawrence Lessig, de la Universidad de Stanford, y James Boyle, de la Duke Law School, inspirándose en la obra de Richard Stallman y en los trabajos de la Free Software Foundation (FSF). Como hemos mencionado antes, Stallman creó la General Public License (GPL) para difundir tibres de permisos" los programas de ordenador bajo una única condición: la de no poner obstáculos a la circulación de los programas modificados en virtud de una GPL. Respecto a estos programas no se requiere autorización para acceder a su -ódigo fuente" ni para modificarlo, obtener copia o usarlo con cualquier fin sin ánimo de lucro. Tampoco está sujeta a tal autorización la distribución de los programas modificados ni la realización sobre ellos de los mencionados actos.

¿Por qué las licencias CC tienen interés para la educación y los profesores? La respuesta es sencilla y a la vez compleja. Las escuelas han cambiado y hoy nadie puede pretender enseñar sin tener en cuenta que nuestros alumnos pasan muchísimo tiempo enganchados" a las redes sociales, a las webs y a los recursos digitales. Por tanto, Internet y la propia tecnología están transformando el modo en que los jóvenes aprenden y se socializan en un mundo cada vez más interconectado y con múltiples fuentes de conocimiento (Fitzgerald, 2008). Les cuesta mucho aprender de manera

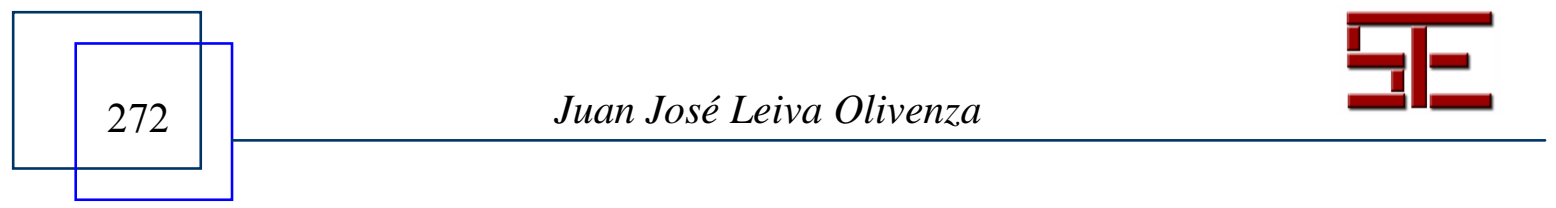




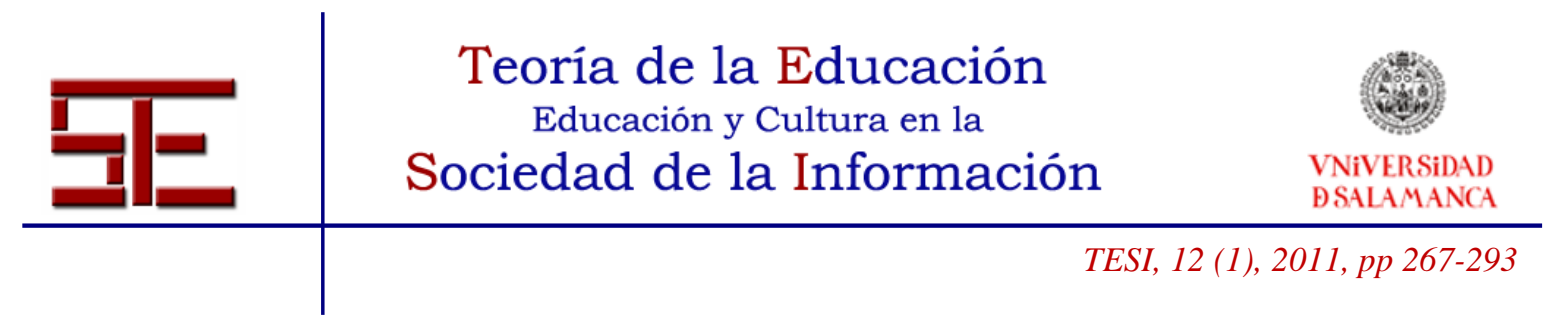

tradicional y aprenden más y mejor empleando las TIC. Además, los recursos educativos ya no son estáticos y escasos, sino que son numerosos y dinámicos, $\mathrm{y}$, muchos de ellos son de libre acceso. De hecho, en muy poco tiempo hemos pasado de una época en la que predominaban los recursos educativos web de acceso restringido a un momento en el que la libre disposición de materiales digitales en diferentes webs nos permite hablar de una auténtica revolución tecnológica silenciosa. Es más, los profesores y alumnos de cualquier lugar del mundo pueden acceder a materiales y contenidos multimedia elaborados por profesores y alumnos de cualquier lugar del mundo. Esta dimensión internacional e intercultural está dotando de una gran riqueza y diversidad la propia interconectividad que está provocando la creación y difusión de una enorme cantidad de contenidos y recursos digitales de libre acceso con licencias CC.

El impacto potencial de la educación digital es enorme, pero también se puede ver obstaculizada por las restricciones legales en materia de propiedad intelectual. En este punto, las licencias CC proporcionan las herramientas necesarias para superar estas restricciones, impulsando la apertura de los recursos educativos de modo que no sólo sean accesibles para alumnos y profesores, sino que éstos puedan adaptar, modificar y transformar para crear nuevos materiales didácticos para la promoción de entornos virtuales de aprendizaje (EVA). Las licencias CC representan una posibilidad de compartir obras creativas por Internet, consintiendo que algunos derechos sobre las mismas estén permitidos para los usuarios.

Ya, en el año 2001, la GPL concebida por la FSF llevaba unos cuantos años de funcionamiento demostrando precisamente como un aprovechamiento de las restrictivas leyes sobre propiedad intelectual se puede emplear para promocionar la copia, uso, modificación y distribución de contenidos software en pro del enriquecimiento cultural de toda la comunidad científica, cultural y educativa. Precisamente, $\mathrm{CC}$ nace a partir del seguimiento de este tipo de iniciativas pioneras, planteando el desafío de la extensión de este tipo de filosofía de producción colaborativa, cooperativa, descentralizada y abierta a otras áreas de producción como la de las obras artísticas, culturales, científicas y educativas.

Cualquier profesor puede usar las licencias CC para escoger los términos de propiedad (copyright) de sus trabajos didácticos, pasando éstos de tener "todos los derechos reservados" a "algunos derechos reservados". Así, los profesores, y también los propios alumnos, pueden proteger y compartir sus obras eliminando la incertidumbre legal que supone que cualquier usuario de la Red pueda bajarse sin problemas de Internet

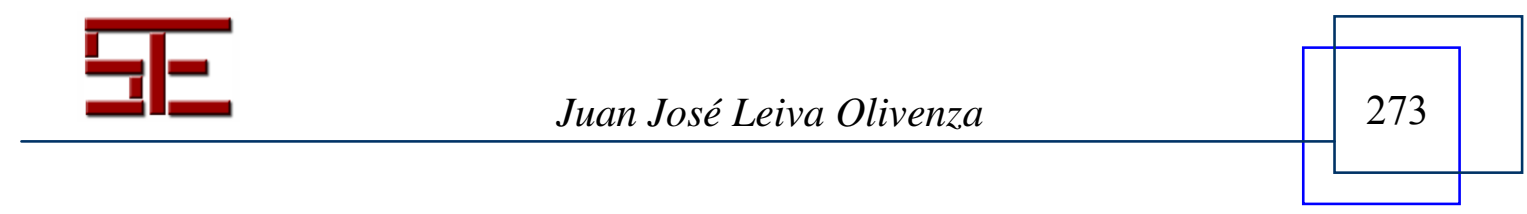




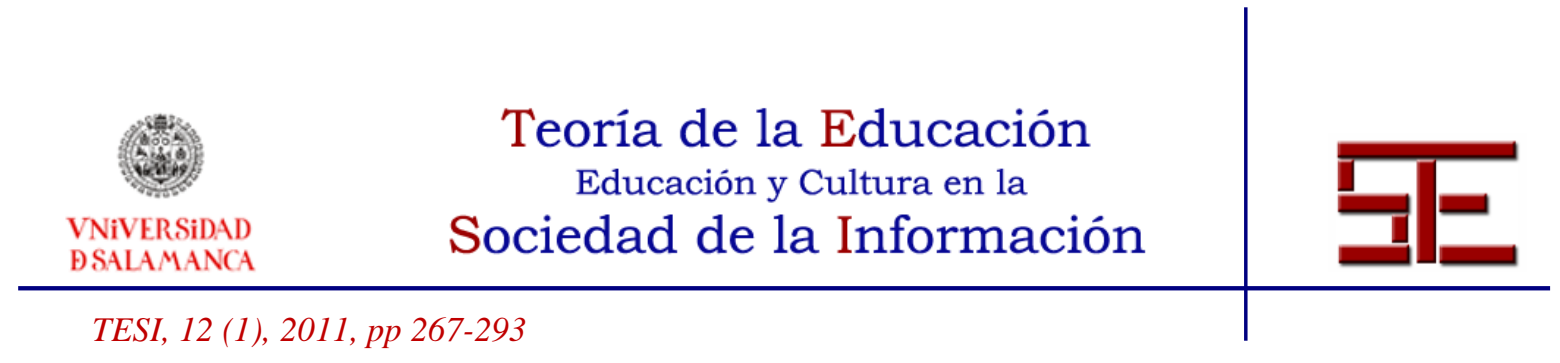

documentos en diversos formatos. Como plantean Sánchez y Ruiz (2007), los creadores pueden definir y delimitar hasta qué punto están dispuestos a compartir los derechos sobre sus trabajos que les otorga la ley. Lógicamente, los usuarios pueden y deben conocer previamente qué pueden hacer con una obra.

Como las licencias originales de CC se basan en la legislación estadounidense (que se halla armonizada, a través de tratados internaciones, con la legislación de otros países), es preciso que dichas licencias se adapten a las particularidades legislativas de cada país. Por este motivo las licencias deben adaptarse específicamente, por abogados locales, a la regulación de cada país. En el caso de España nuestra Ley de Propiedad Intelectual (Ley 23/2006) indica en su artículo 17:

Corresponde al autor el ejercicio exclusivo de los derechos de explotación de su obra en cualquier forma $y$, en especial, los derechos de reproducción, distribución, comunicación pública y transformación, que no podrán ser realizadas sin su autorización, salvo en los casos previstos en la presente Ley.

De esta forma, si una persona indica que su obra tiene una licencia $\mathrm{CC}$ esto no se contrapone en absoluto con lo regulado en la ley, ya que es dueño y señor de su obra y puede hacer con ella lo que quiera. Por tanto, las licencias CC son compatibles con nuestra legislación. También cabe señalar que entre los objetivos primordiales de CC no encontramos el de recoger licencias que amparen los programas de software libre. De hecho, para el caso del software CC recomienda explícitamente el uso de las licencias ofrecidas por la FSF y la Open Source Initiative (OSI). Debemos considerar por tanto las licencias CC como un complemento, y no como un sustituto, de las licencias del mundo del software libre, puesto que de hecho están orientadas a otros entornos de creación, sobre todo, en el ámbito de la creación de contenidos, como imágenes, sonidos, vídeos o textos.

Por tanto, las licencias CC tienen un enorme interés para los profesionales de la educación ya que vienen a proporcionar la infraestructura legal y técnica esencial para el éxito a largo plazo de los EVA, haciendo posible que los recursos educativos pasen a ser ampliamente accesibles, adaptables, interoperables, interactivos e interculturales.

Otro aspecto que debemos destacar es que CC facilita la innovación y la colaboración en el ámbito educativo, ya que ayudan a los educadores a ampliar el impacto de sus propios recursos educativos en Internet. En este sentido, profesores, centros educativos, grupos universitarios de investigación en Tecnología Educativa, así como las propias administraciones educativas están incorporándose a esta dinámica de creación y

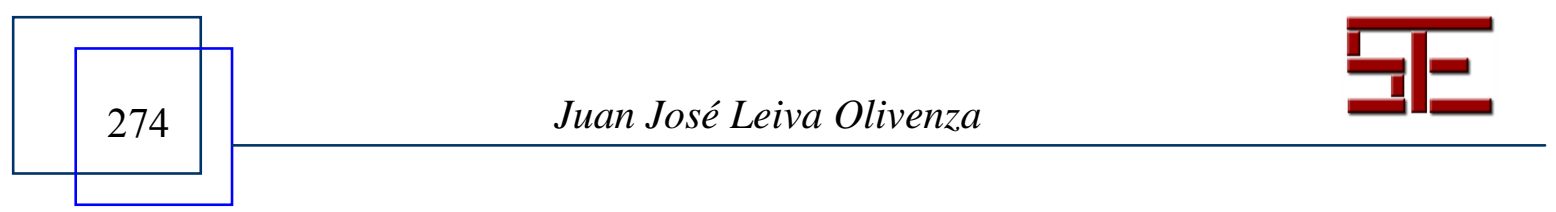




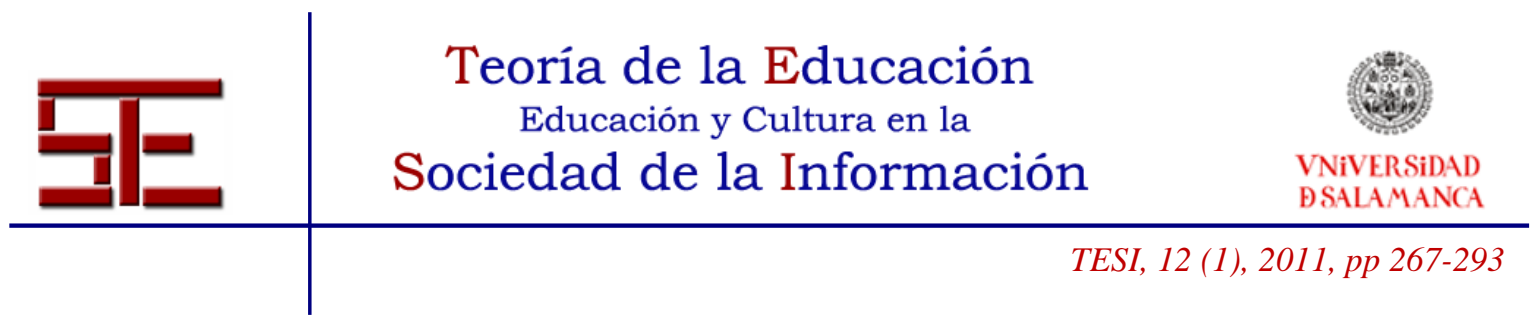

difusión libre que facilita la innovación educativa y permite el intercambio y uso libre de una enorme cantidad de recursos educativos (Castillo, 2007). De hecho, un número creciente de los creadores de los recursos educativos con licencias $\mathrm{CC}$ son de autodistribución, es decir, permiten que sus obras se difundan abiertamente a través de Internet, utilizándolas en plataformas de e-learning y fomentando los EVA.

Una cuestión que los docentes tienen que conocer de manera nítida es que no se puede confundir - Creative Commons" con eopyleft" o todo libre". Creative Commons plantea un paso intermedio entre el férreo sistema de copyright y el tibre total" (que cualquiera pueda hacer lo que quiera con las obras que se encuentre). Se coloca en una posición intermedia y pone a disposición de los autores licencias "a la carta", cuya redacción se incorpora al espacio o soporte donde está la obra y donde se regulan los usos autorizados por el autor con respecto a la referida obra. Esto, evidentemente, también permite que los autores puedan decidir que su obra pase automáticamente a dominio público, lo cual tiene enormes ventajas para aquellos profesores que quieren difundir sus trabajos didácticos en todo el mundo y con todo el mundo (Barandiarán, 2003). Y esto es muy relevante, es decir, el hecho de que se permita esta difusión virtual tiene extraordinarias potencialidades de conocimiento y de intercambio, pues supone que cualquier docente de cualquier lugar del planeta pueda acceder a un trabajo y pueda continuarlo, difundirlo, modificarlo, ampliarlo, en la medida en que otorguemos como creadores o productores de material didáctico virtual licencias $\mathrm{CC}$ que así lo permitan. Y llegamos a una clave fundamental de las licencias $\mathrm{CC}$, y es la flexibilidad que adoptan para el creador en la medida en que las características de estas licencias las hacen particularmente atractivas para aquellos autores noveles (o no) que, deseando distribuir y dar a conocer su obra por Internet, prescinden de los ingresos de comercialización y la ponen a disposición de todo el mundo de forma gratuita (Xalabarder, 2006). En este punto, estamos mencionando que subyace una perspectiva pedagógica de cooperación y de intercambio que permite a los docentes compartir sus trabajos, sus presentaciones, sus materiales didácticos, y ponerlos al servicio de otros profesores para que puedan ser empleados en otros contextos de aprendizaje, con toda la riqueza que supone esta idea desde un punto de vista didáctico abierto a la innovación y al escrutinio público. En realidad, la lógica de las licencias $\mathrm{CC}$ cabe entenderla desde una perspectiva pedagógica abierta, ya que va dirigida principalmente a aquellos profesores cuyo interés predominante sea el de que sus trabajos didácticos circulen de la forma más amplia y rápida posible en Intenet. En este punto, Sánchez y Ruiz (2007) parten de una serie de preguntas de interés para la reflexión didáctica de profesionales de la educación: ¿Quién no ha buscado información en Internet para elaborar

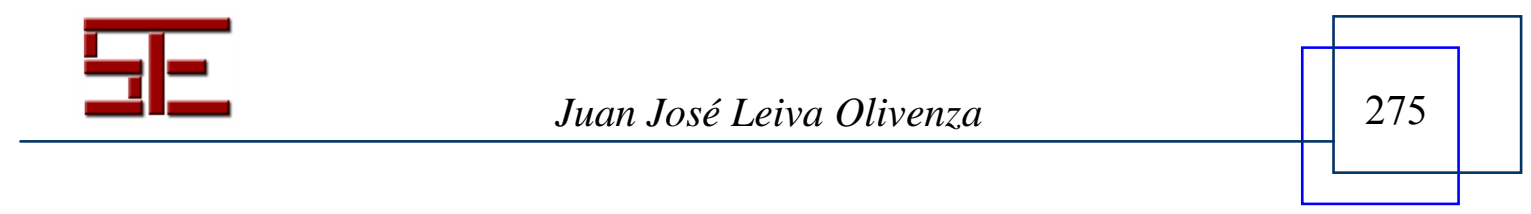




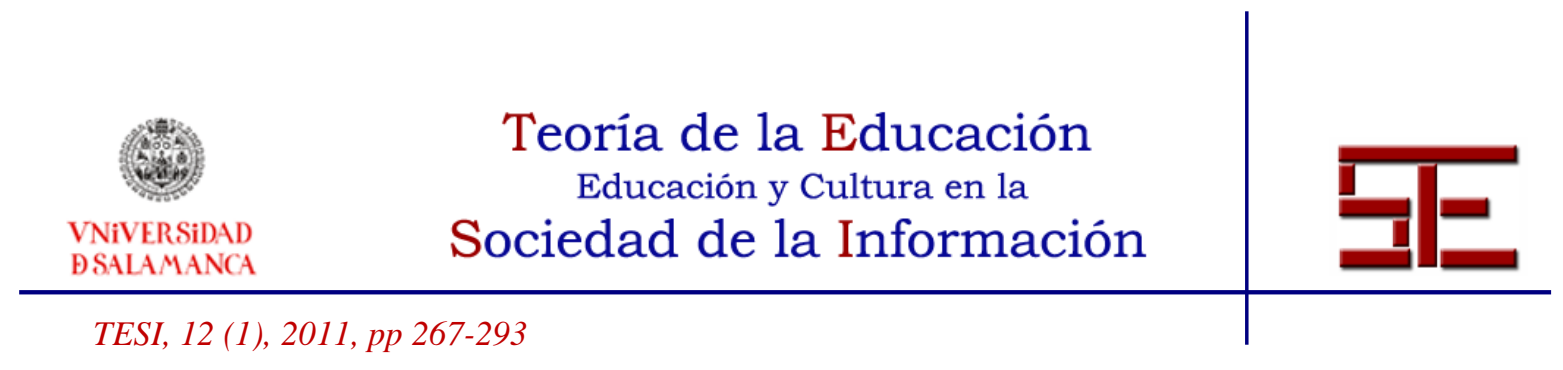

documentos propios?, ¿cuántas veces hemos buscado fotografías e imágenes (por carecer de ellas) para ilustrar un trabajo y no las hemos encontrado? (o si lo hemos hecho tenían una licencia que no nos permitía su uso sin pedir permiso al autor, permiso que en la mayoría de las ocasiones no recibíamos). Si hubiésemos encontrado la información que necesitábamos, la imagen que nos era útil... lo habríamos agradecido seguro.

Por tanto, compartir con los demás nuestro trabajo es un ejercicio de buena práctica que repercutirá en nosotros mismos. Y se comparte de todo: fotografías, música, cursos... en medio de esta revolución de la Internet" en la que los usuarios pasan de ser meramente consumidores de cultura a productores, creadores de dicha cultura (Vercelli, 2006). Pero compartir no tiene que significar regalar", no quiere decir que cualquiera se pueda atribuir nuestro trabajo. La mayor parte de los creadores no desean poner a sus obras el símbolo (c) identificativo del "copyright", acompañado de la frase "todos los derechos reservados" porque en multitud de ocasiones no refleja necesariamente sus intereses y pretensiones cuando publican algo en Internet. Ciertamente, Creative Commons busca con estas licencias fomentar la reutilización creativa de todo tipo de obras intelectuales, permitiendo al mismo tiempo que el creador mantenga los derechos que considere oportunos. Para ello pone a disposición de los autores en su página web unos formularios que permiten elegir las características con las que el creador quiere distribuir su obra.

\section{TIPOS Y CARACTERÍSTICAS DE LAS LICENCIAS CC}

Tenemos que destacar la diversidad de licencias CC, lo cual es algo positivo para definir el trabajo que cualquier docente quiere poner a disposición de otros docentes en la Red. Una vez completado el formulario correspondiente en el siguiente enlace: http://es.creativecommons.org/, el sistema genera una licencia en tres formatos. En primer lugar, se expone un resumen de uso para autorizados. En segundo lugar, un texto legal y, finalmente, una versión digital con metadatos que se pueden usar para facilitar el trabajo de los buscadores web, a los efectos de que puedan utilizar bajo ciertas condiciones el contenido del trabajo realizado y colgado en Internet.

Como ya hemos comentado con anterioridad, las licencias CC están inspiradas parcialmente en las del software libre, aunque es muy importante destacar que no han sido creadas para su aplicación a programas de software, sino a todo tipo de contenidos y documentos (de texto, de audio, vídeo, etc..). Los profesores creadores o productores

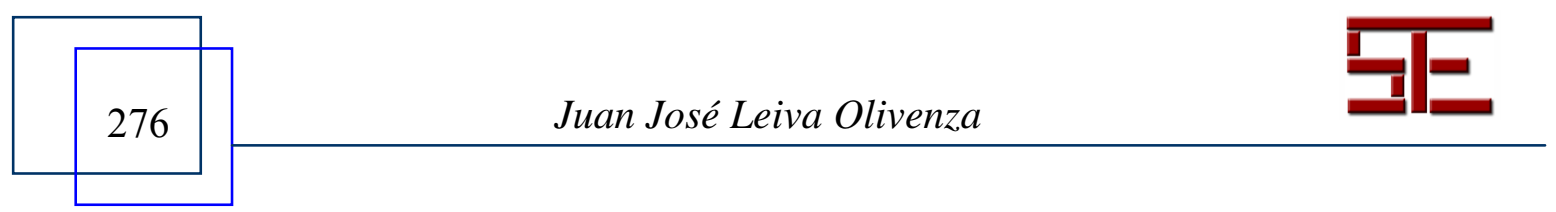




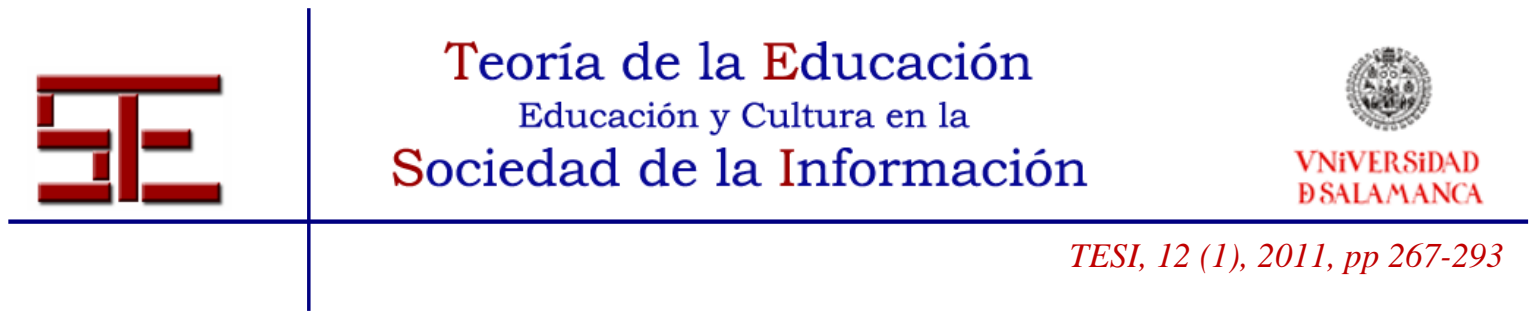

de material multimedia o de contenido virtual pueden elegir entre una serie de seis licencias CC que están libres de carga, fácil de usar, y ayudan a normalizar lo que es abierto y libre en Internet (Dulong, 2006). En este sentido, un titular de los derechos puede elegir una o más de las licencias CC existentes. En el sitio Web de Creative Commonns en España se encuentran recogidos los tipos de licencia (que recogemos literalmente a continuación). Hay que subrayar que una licencia CC no invalida o altera el copyright de una obra, sino que permite el reconocimiento de algunos derechos a terceras personas con una serie de condiciones (cuatro) que componen seis licencias CC. Estas son las condiciones existentes:

BY: Reconocimiento (Attribution): El material creado por un artista puede ser distribuido, copiado y exhibido por terceras personas si se muestra en los créditos.

No Comercial (Non commercial): El material original y los trabajos derivados pueden ser distribuidos, copiados y exhibidos mientras su uso no sea comercial.

= Sin Obra Derivada (No Derivate Works): El material creado por un artista puede ser distribuido, copiado y exhibido pero no se puede utilizar para crear un trabajo derivado del original.

(0) Compartir Igual (Share alike): El material creado por un artista puede ser modificado y distribuido pero bajo la misma licencia que el material original.

Estas son las licencias CC que puede escoger cualquier autor para la difusión de sus trabajos en la Red:

Reconocimiento: El material creado por un artista puede ser BY. distribuido, copiado y exhibido por terceros si se muestra en los créditos.

Reconocimiento - Sin obra derivada: El material creado por un

BY: $=$ artista puede ser distribuido, copiado y exhibido por terceros si se muestra en los créditos. No se pueden realizar obras derivadas.

Reconocimiento - Sin obra derivada - No comercial: El material creado por un artista puede ser distribuido, copiado y exhibido

BY: $=0$ por terceros si se muestra en los créditos. No se puede obtener ningún beneficio comercial. No se pueden realizar obras derivadas.

BY Reconocimiento - No comercial: El material creado por un artista puede ser distribuido, copiado y exhibido por terceros si se

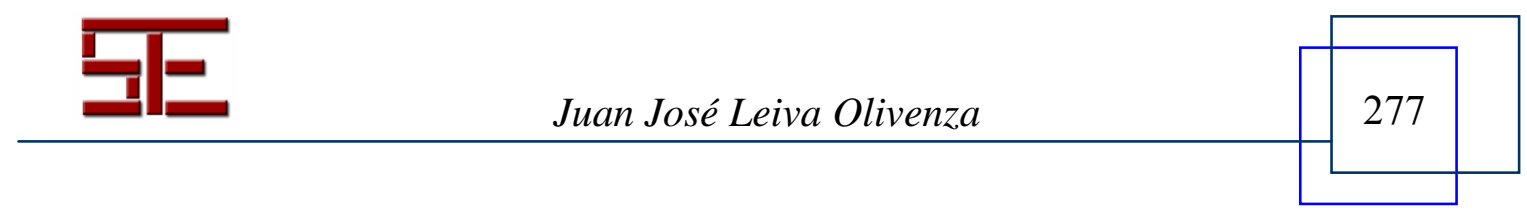




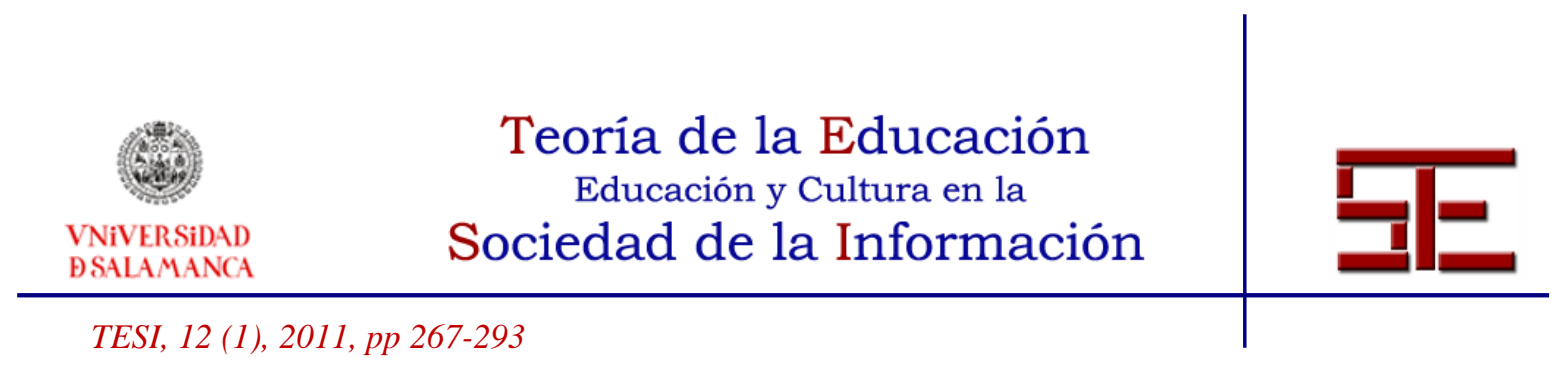

muestra en los créditos. No se puede obtener ningún beneficio comercial.

Reconocimiento - No comercial - Compartir igual: El material creado por un artista puede ser distribuido, copiado y exhibido BY: 10 por terceros si se muestra en los créditos. No se puede obtener ningún beneficio comercial y las obras derivadas tienen que estar bajo los mismos términos de licencia que el trabajo original.

Reconocimiento - Compartir igual: El material creado por un BY: (O) artista puede ser distribuido, copiado y exhibido por terceros si se muestra en los créditos. Las obras derivadas tienen que estar bajo los mismos términos de licencia que el trabajo original.

Para poder disponer de estas licencias e incluirlas en nuestro trabajo, generalmente en la contraportada del mismo, o bien, en la propia web donde alojamos el mismo, sólo debemos responder a un par de preguntas en el sitio web de CC y el sistema nos facilita un icono para incluir en las páginas que queramos (en forma de comandos HTML para copiar y pegar). Ciertamente, el hecho de poder acceder a páginas y recursos que tienen licencias CC ayuda muchísimo para disponer de información y de todo tipo de documentos que, en un momento dado, podemos necesitar para ilustrar un trabajo didáctico o realizar una webquest. En este sentido, un ejemplo sencillo radica precisamente en disponer de fuentes bibliográficas virtuales relevantes para la búsqueda de documentación e indagación en una temática en concreto, de hecho ya hay periódicos y revistas que tienen licencias $\mathrm{CC}$, lo cual es una ventana abierta para poder acceder a documentos visuales y textuales que podamos emplear libremente.

Lógicamente, todas las licencias $\mathrm{CC}$ requieren que los docentes u otras personas que utilicen el trabajo en cuestión tengan que darle crédito de la manera que el creador solicita, es decir, que sólo puede emplear el contenido del trabajo según las condiciones definidas y explicitadas en la correspondiente licencia CC. Por tanto, si elaboramos en nuestro instituto una web donde alojamos trabajos educativos de nuestro alumnado, y lo elaboramos con programas libres, estamos en condiciones de otorgar alguna de las licencias $\mathrm{CC}$ y difundir esos trabajos. Es decir, podemos consentir a otros copiar, distribuir, mostrar, ejecutar y modificar nuestro trabajo, siempre y cuando distribuyan el mismo en las mismas condiciones. Esto confiere a los trabajos desarrollados bajo esta licencia unas pinceladas de creatividad y de cooperación virtual, consciente o

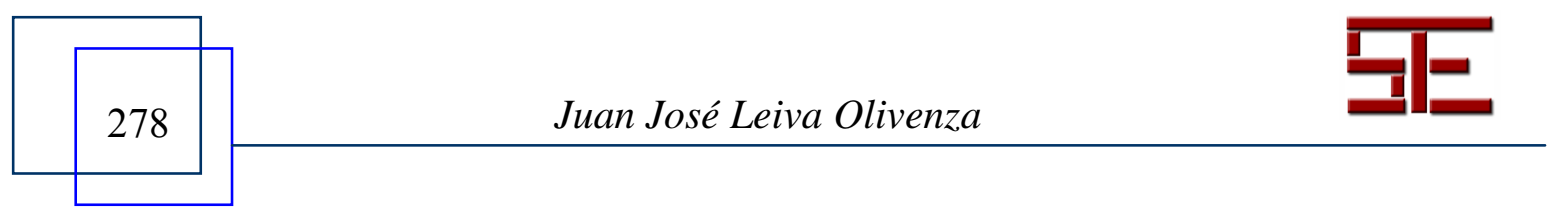




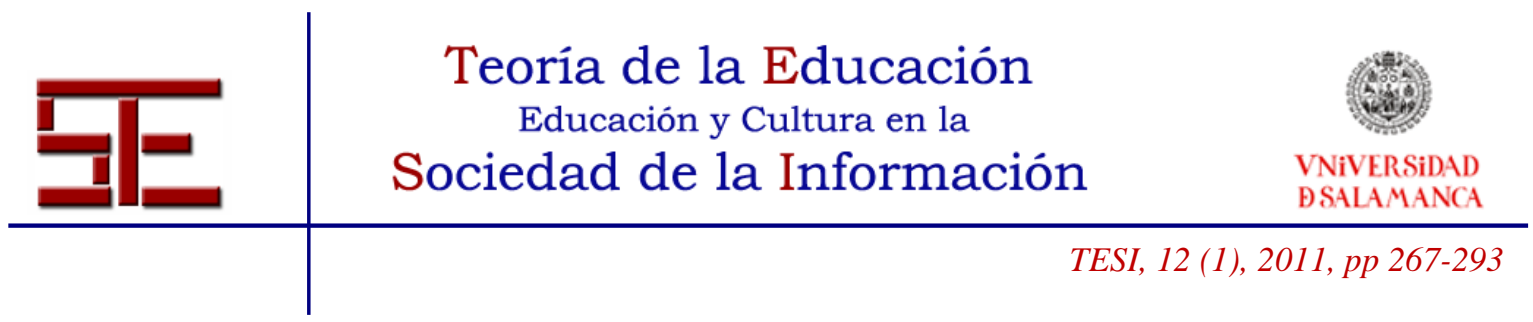

inconsciente, que es sumamente enriquecedora desde una perspectiva abierta y democrática. En definitiva, estas licencias vienen a posibilitar una extensión libre y colaborativa de todo tipo de documentos y de recursos virtuales que pueden ayudar a crear verdaderas comunidades de aprendizaje en grupos sociales muy heterogéneos. Además, en el caso concreto del docente, entendido como productor de contenidos y materiales multimedia, resulta extremadamente sugerente la idea de que los profesores a través de las redes sociales puedan hacer más y mejores herramientas didácticas virtuales gracias a las licencias CC y, sobre todo, enriquecer sus trabajos con las aportaciones de profesionales que creen en un mundo virtual $-\mathrm{y}$ real- más abierto $\mathrm{y}$ plural, y menos sujeto a los condicionantes no siempre benevolentes de las grandes industrias o marcas culturales (Cabello, 2005).

En este punto, cabe mencionar que Creative Commons ofrece las licencias más utilizadas de contenido abierto en el mundo, y que han sido legalmente $\mathrm{y}$ lingüísticamente adaptadas a más de 50 jurisdicciones en todo el mundo (De la Cueva, 2005). Los órganos gubernamentales, universidades y bibliotecas de todos los países pueden aprovechar las licencias CC para aumentar el acceso y el impacto de sus recursos, y en el caso de las instituciones y administraciones educativas, pueden favorecer el impulso del e-learning. Además, la mayoría de los autores, sin importar su campo de actividad, ni su condición de aficionado o profesional, tienen un auténtico interés por favorecer un ecosistema en el que las obras puedan propagarse, reutilizarse y transformarse de forma creativa. Esto es algo fundamental, el hecho de construir en la Red un ecosistema educativo aglutinador de trabajos diversos y abiertos a la creatividad de otros profesionales de la educación preocupados en mejorar su docencia, en potenciar la página web de su centro educativo en cuanto a recursos virtuales se refiere, o difundir sus materiales didácticos a un número mayor de profesores o instituciones escolares que empleen las TIC como elemento fundamental en sus diseños curriculares (Codina, 2009). De hecho, la idea de la interculturalidad en la Red tiene sentido en la medida en que consideremos que cuanto más sencillo es reutilizar y derivar trabajos, más ricas se hacen nuestras culturas, y no sólo profesionales o incluso virtuales sino en su complejidad global.

\section{EL DOCENTE ANTE LAS LICENCIAS CC: DEL CONSUMO A LA CREACIÓN Y DIFUSIÓN DE MATERIALES DIDÁCTICOS}

Hasta ahora hemos defendido la idoneidad de emplear licencias CC para consolidar la difusión, promoción y apertura de los trabajos y producciones multimedia de los

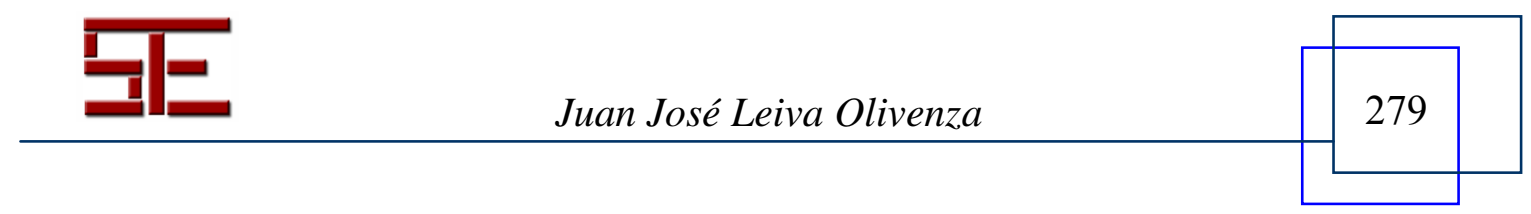




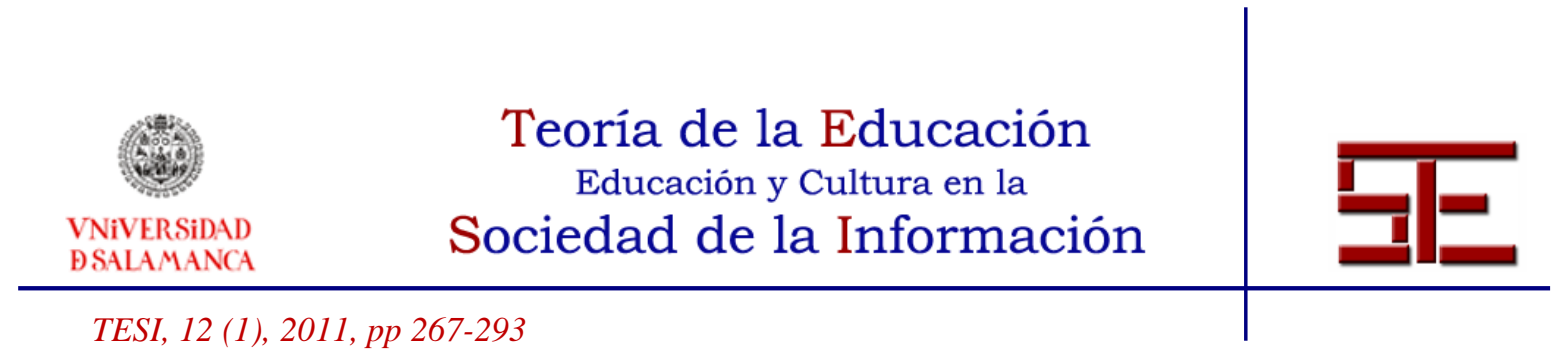

profesores a través de plataformas virtuales que estén abiertas no sólo al consumo de los mismos, sino que éstos sirvan a su vez para conformar nuevas creaciones y usos significativos para una educación más eficaz y motivadora para el alumnado de hoy. Pero, ¿cuáles son las razones para promover ese cambio de mentalidad en el profesorado? O, dicho de otra forma, ¿qué beneficios supone para el profesorado percibirse y sentirse de consumidor a ser creador y difusor de materiales didácticos virtuales con licencias CC? Bien, a continuación vamos a centrarnos en cuáles son los beneficios que tanto para el alumno como para el docente tiene la aplicación de las TIC en una educación abierta gracias al empleo y uso de contenidos virtuales con licencias $\mathrm{CC}$.

En primer lugar, el interés por la materia es algo que a los docentes puede costar más de la cuenta dependiendo simplemente del título de la misma materia que vayamos a impartir. Cuando hablamos, por ejemplo, del área de matemáticas el simple término ya puede desmotivar a algunos alumnos, sin embargo, el docente que imparta dicha materia y utilice habitualmente medios informáticos o bien otras herramientas comunicativas virtuales atrae al alumno y le hace perder miedo a ese concepto inicial de miedo al área de matemáticas. Es más sencillo que el alumno tome más interés por las distintas áreas conociendo la metodología que el docente aplica habitualmente en su proceso de enseñanza-aprendizaje. En este punto, la diversidad de contenidos multimedia abiertos a la difusión y a su reutilización reflexiva por parte de los docentes es un aspecto fundamental en las que las licencias $\mathrm{CC}$ tienen mucho que decir, y planteamos esto en la medida en que los propios portales de educación de numerosas comunidades autónomas, así como de particulares y asociaciones profesionales, científicas (e incluso de editoriales) ofrecen sus recursos didácticos de manera abierta con licencias CC.

En segundo lugar, y relacionado con lo anterior, hay que subrayar la motivación. El alumnado se encontrará más motivado si la materia es atractiva, amena, divertida, si le permite investigar de una forma sencilla utilizando las herramientas TIC y si se le permite aprender jugando e investigando. Quizá esta ventaja es la más importante puesto que el docente puede ser muy buen comunicador pero si no tiene la motivación del grupo será muy difícil que consiga sus propósitos didácticos.

En tercer lugar, podemos citar la interactividad como otro beneficio fundamental. E1 alumno puede interactuar, se puede comunicar, puede intercambiar experiencias con otros compañeros del aula, del centro educativo o bien de otras instituciones escolares o socioculturales. Ello enriquece en gran medida su aprendizaje, haciéndolo más intercultural e inclusivo, abierto y democrático. De esto hay muchas experiencias o

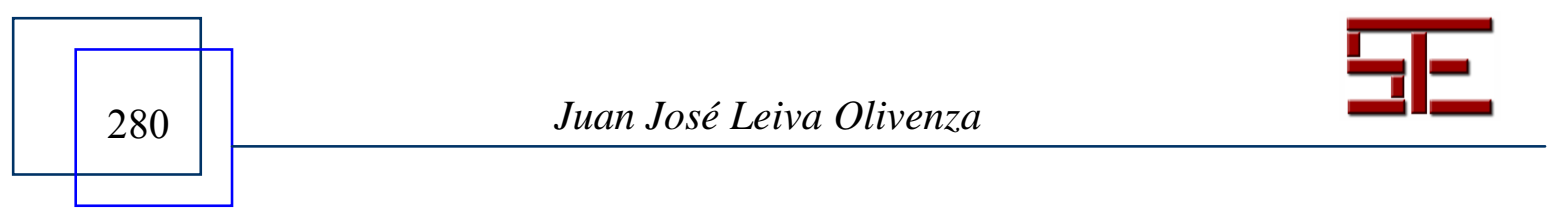




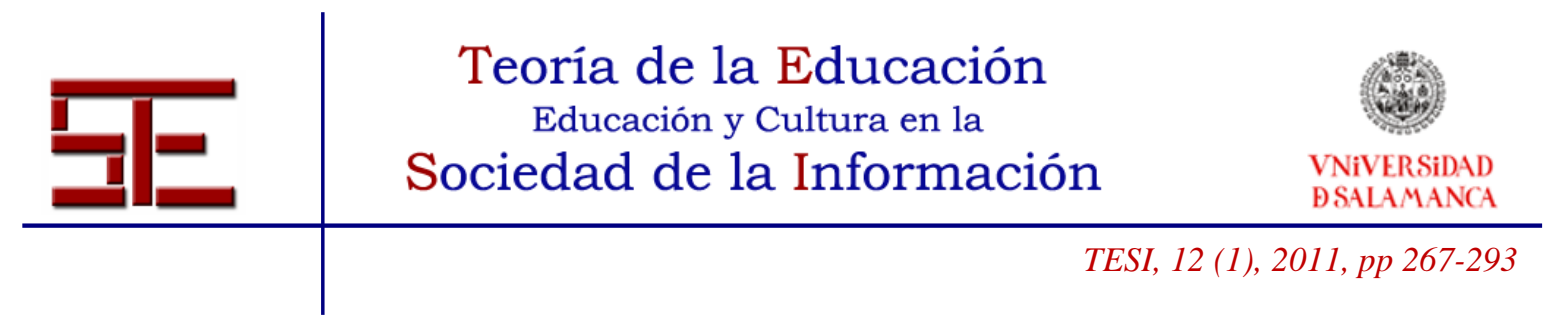

ejemplos, cada día más, de juegos o proyectos que la administración educativa propone al equipo docente y al alumnado de las distintas etapas, sobre todo en el ámbito de la educación en valores (educación ambiental, educación intercultural, educación para la salud, et.). Además, es importante reseñar que la interactividad también hace referencia a la competencia que tiene el docente para interactuar e intercambiar materiales didácticos con licencia $\mathrm{CC}$ en el marco de plataformas o comunidades virtuales de aprendizaje de carácter regional, nacional e internacional. Ésa es la facilidad que nos ofrece la web 2.0.

En cuarto lugar, tenemos que mencionar la cooperación. Las TIC, utilizando la interactividad que le permite al alumno y al profesorado comunicarse de manera permanente, también posibilita el diseño y la realización de experiencias, trabajos o proyectos en común. Es más fácil trabajar juntos, aprender juntos, e incluso enseñar juntos, si hablamos del papel de los docentes. No nos referimos sólo al alumnado, también el docente puede colaborar con otros docentes, formarse a través de las redes virtuales de aprendizaje y, por tanto, compartir y utilizar recursos que han funcionado bien en determinadas áreas curriculares o programas de las que el alumno será el principal beneficiario. Así mismo, debemos pensar en la potencialidad de este beneficio, y es que la cooperación es un valor en alza en Internet, ya que cada vez son más las comunidades de aprendizaje que emplean el e-learning para promover y difundir sus trabajos con licencias $\mathrm{CC}$.

En quinto lugar, tenemos la promoción del aprendizaje en feed back", o la denominada retroalimentación. Esto tiene que ver, sobre todo, con la forma novedosa en que los estudiantes pueden emplear las plataformas virtuales para aprender más y mejor. Esto significa que hoy en día es mucho más sencillo corregir los errores que se producen en el aprendizaje, puesto que éste se puede producir "justo a tiempo", es decir, mientras el alumno aprende, puede cometer lógicamente uno o varios errores, y sigue aprendiendo en ese mismo momento, sin necesidad de que el profesor esté pendiente de dicho proceso, ya que las propias herramientas virtuales (como cuestionarios y webquest) son las que a través de la interacción con el alumno resaltan los errores que éste comete, promoviendo esa retroalimentación tan necesaria en la construcción de aprendizajes eficaces y funcionales.

En sexto lugar, el desarrollo de la iniciativa del alumno, el desarrollo de su imaginación y el aprendizaje por sí mismo también es una ventaja de estos recursos. Y qué decir tiene de la creatividad del profesorado en la creación y difusión de sus trabajos a través

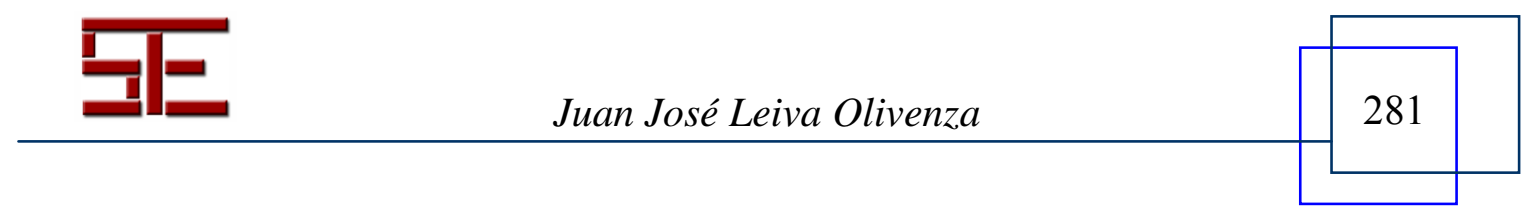




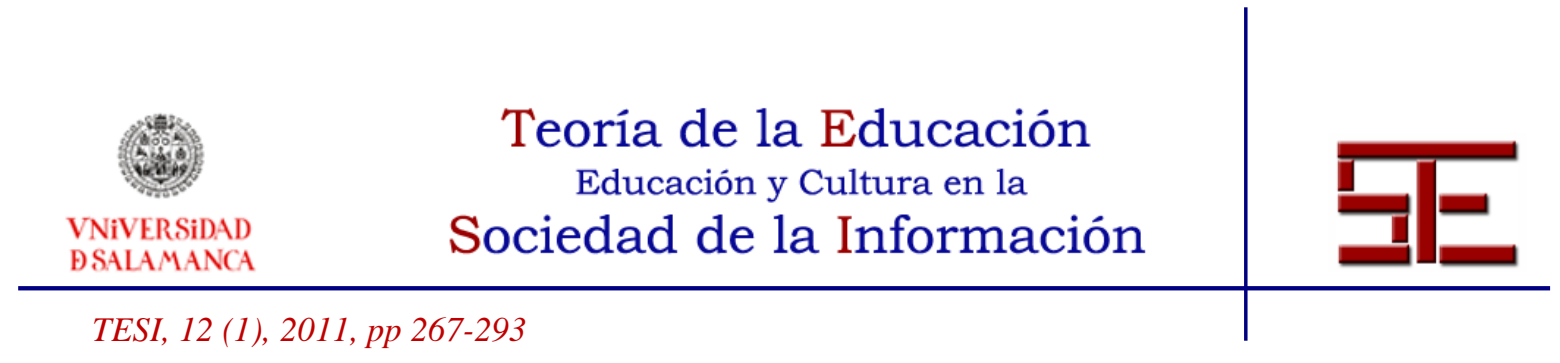

de los mencionados canales de interacción virtual y promoviendo contenidos virtuales con licencias CC.

En séptimo lugar, tendríamos el beneficio de la comunicación. Esto es obvio pero de manera ineludible tiene que quedar claro en el establecimiento de interacciones efectivas y positivas entre el docente y el alumnado en los EVA. Todo lo que venimos exponiendo tiene sentido si la relación educativa en el marco de la educación virtual se basa en la interconectividad y la flexibilidad. Una relación que además promueve la libertad de enseñar y de aprender, lo cual es un beneficio en una sociedad cada vez más compleja y diversa. Además, la comunicación educativa en plataformas de e-learning ya no es tan formal, sino eminentemente directa y mucho más abierta $\mathrm{y}$, por supuesto, naturalmente imprescindible, no sólo entre profesorado y alumnado, sino también entre los propios estudiantes en comunidades virtuales de aprendizaje a través de las redes sociales.

Finalmente, hay que señalar la importancia de la autonomía del aprendizaje. Si hasta hace apenas unos años la información era suministrada en gran medida por el profesor en la tradicional clase presencial, y las fuentes de conocimiento eran mucho más escasas -biblioteca del colegio o instituto, del barrio o de la localidad; en los medios de información, siempre en formato impreso- para el propio alumnado. Existía una mayor dependencia del canal de comunicación que el profesor transmitía al alumno. Ahora, con la llegada de las TIC y el fuerte impulso de Internet, conjuntamente con la dirección o guía de un profesorado formado en EVA, el alumno dispone de infinito número de canales y de gran cantidad de información y documentos, muchos de ellos de libre acceso y con licencias $\mathrm{CC}$ que permiten su reutilización para profundizar en un aprendizaje más autónomo y flexible. Por tanto, la flexibilidad y la autonomía del aprendizaje son beneficios a los que contribuye de manera decidida la extensión de trabajos y webs que emplean licencias CC, ya que para buscar y aprovechar educativa esos documentos textuales o audiovisuales no es necesario pedir permisos especiales, sino que docentes y alumnos son conocedores de sus licencias, y por tanto conocen hasta qué punto pueden utilizarla y modificarla (Lessig, 2009). Esta labor es muy importante e implicará por parte del docente un esfuerzo para cambiar la mentalidad de muchos jóvenes que, bien por desconocimiento o por otras razones, no son conscientes de la importancia de reconocer y valorar el trabajo ajeno, y que sus trabajos reconozcan el valor de los diferentes creadores de contenidos multimedia en Internet es una cuestión de educación en valores por parte de los docentes comprometidos por un uso legítimo y crítico de las TIC en la educación.

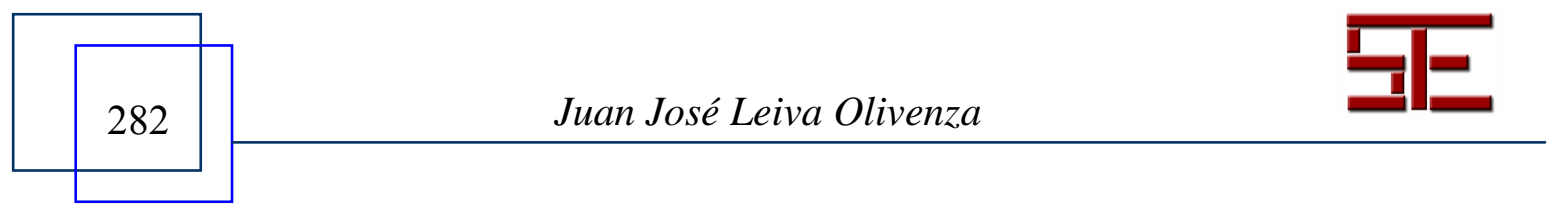




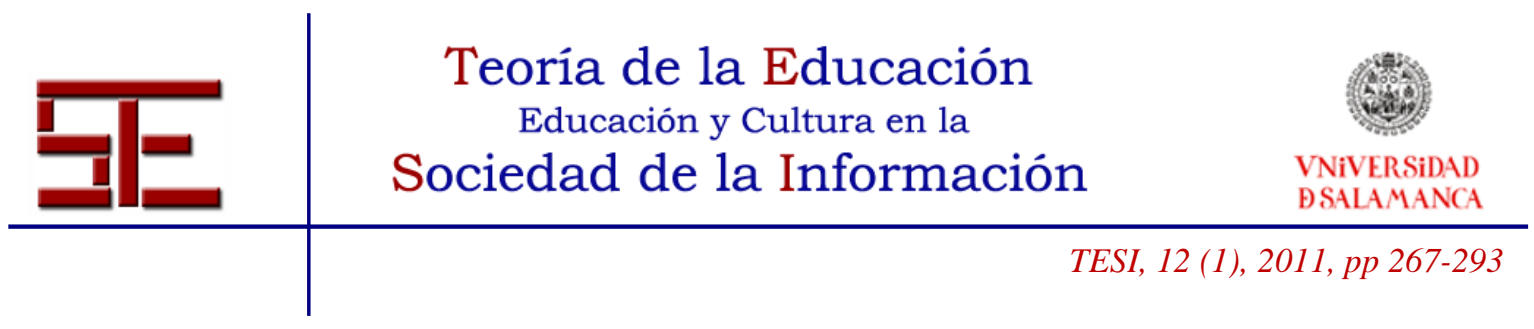

Si el trabajo de un alumno o grupo de alumnos va a ser publicado en Internet, y esto supone -quedar bien", pues debemos enseñarles a presentar bien los trabajos, y esto implica un reconocimiento para el esfuerzo de nuestro alumnado que es protagonista de su propio aprendizaje. Publicar en Internet es sumamente motivador e implica una dosis de autoestima en el alumno o grupo. Además esto ayuda al docente para promocionar en clase un clima más cohesionado de aprendizaje al tener más importancia su trabajo y para este alumnado las licencias CC pueden ser herramientas fundamentales en la difusión y aprovechamiento de muchas iniciativas y proyectos de aprendizaje a través de la Red.

Con respecto al docente, su clase es la misma, pero tal vez consiga que haya una mayor capacidad de trabajo en equipo, que haga reflexionar al alumno en sus comentarios particulares en los blogs, o favoreciendo que el alumnado sea también creador de webquest y webs colaborativas. Por tanto el docente debe ser conocedor de las normas de protección intelectual y animar a su alumnado a obtener documentos que tengan licencias $\mathrm{CC}$ y a reutilizarlos de la mejor manera posible. Por esta razón, hemos de subrayar que el docente debe tener una buena formación en el uso de todas estas herramientas (también de las licencias y programas de software libre) que le facilita Internet, para usarlas en clase, teniendo siempre por delante los objetivos educativos a los objetivos meramente tecnológicos (Sáenz, 2007). Es decir, las herramientas han de ser instrumentos fundamentales que ayuden al docente de la mejor planificación en el proceso de enseñanza-aprendizaje, pero no caer en la trampa tecnológica de un activismo que no tenga guías pedagógicas ni resultados de aprendizaje adecuados (Unesco, 2002).

El uso de las licencias CC tiene enormes potencialidades y puede posibilitar el empleo en clase de metodologías cooperativas, y es que se requiere el trabajo en equipo en clase, o con e-mail, chat o wiki para la realización de elaboraciones didácticas sobre diferentes áreas curriculares. También aparece aquí como un elemento clave el desarrollo de la creatividad por parte del alumnado y el reconocimiento a esa creatividad que puede ser difundida y promovida a través de la web del instituto o del colegio, o bien -eolgada" en páginas oficiales de las administraciones educativas (Lessig, 2008). Además, estas administraciones así como empresas y fundaciones privadas están incentivando en diferentes convocatorias, premios y concursos lo que sería la creatividad en la elaboración de trabajos que promuevan el empleo crítico de los EVA. De hecho, todos los años el Instituto de Tecnologías Educativas (ITE) del

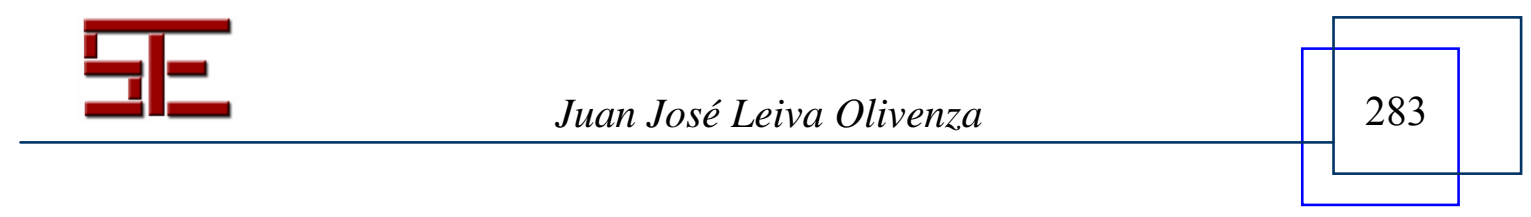




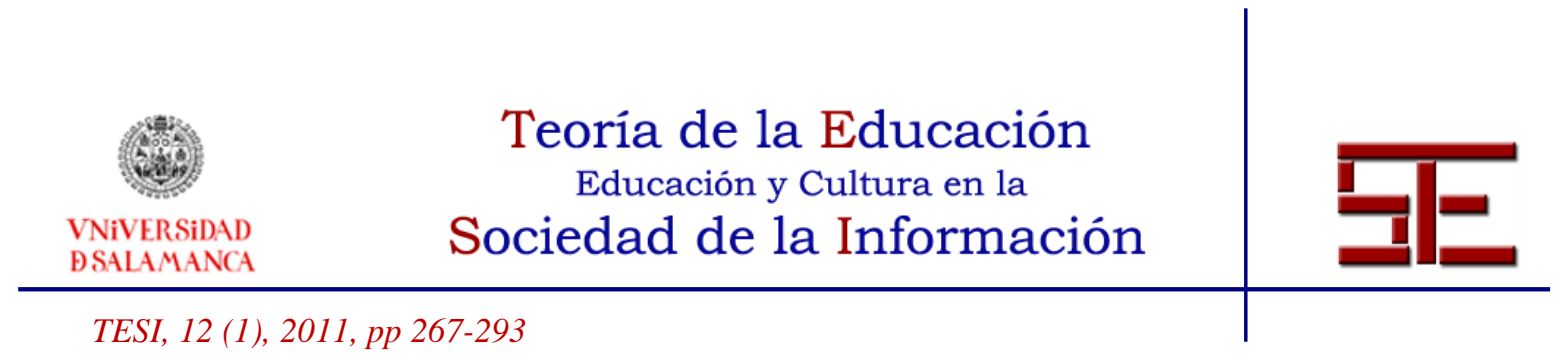

Ministerio de Educación y Ciencia (MEC) convoca los Premios al desarrollo de Materiales Educativos, con el fin de estimular y reconocer la tarea del profesorado y otras personas e instituciones en la producción de recursos basados en las tecnologías de la información y la comunicación. La convocatoria de estos premios favorece la creación de recursos multimedia de contrastada eficacia didáctica, accesibles, ajustados a los contenidos curriculares vigentes en las enseñanzas preuniversitarias y susceptibles de ser usados en el aula o en el hogar por parte del profesorado, el alumnado y las familias.

Así pues, en todo este proceso el papel del docente en clase ha de ser como un acompañante o guía del aprendizaje, es decir, cuando proponemos a los alumnos, por ejemplo, crear un edublog, deberán hacer un guión de lo que van a comentar o plantear reflexiones sobre documentos que se trabajan en clase o están subidos en la web o plataforma que utilizamos en la asignatura correspondiente; las imágenes que tendrá ese blog, si van a añadir música, etc. Y todo ello con la precaución o mejor dicho con el conocimiento de buscar documentos que tengan licencias CC. Por ejemplo, pueden bajarse música de manera legal en http://freemusicarchive.org/, o una gran cantidad de imágenes en la web http://flickrcc.bluemountains.net/, o bien a través de un enlace del Ministerio de Educación como es http://recursostic.educacion.es/bancoimagenes/web/. De hecho, hay ya un número muy elevado de webs en España con licencias $\mathrm{CC}$, y hay que señalar que el proyecto CC España se inicia en febrero del año 2003 cuando la Universidad de Barcelona (UB) decide buscar un sistema para publicar material docente siguiendo el ejemplo del Massachusets Institute of Technology. Se decide optar por el sistema de licencias CC y se establece un acuerdo de trabajo por el cual la UB lideraría el proyecto de adaptación de las licencias al Estado Español en castellano y catalán. En este punto cabe decir que Yahoo ha creado un buscador especial para obras licenciadas bajo CC (http://search.yahoo.com/cc); también Google, en búsqueda avanzada (http://www.google.com/advanced_search?hl=es) ofrece la posibilidad de búsquedas filtradas por el tipo de licencia de uso con el que se publican las páginas web, y la misma organización pone a disposición de los usuarios un buscador propio de $\mathrm{CC}$ (http://search.creativecommons.org/).

Por tanto, los docentes tenemos muchas opciones si queremos crear nuestro material didáctico en la Red, o utilizar el que se está haciendo para crear unidades o proyectos didácticos a partir de trabajos de otros docentes de diferentes lugares del mundo. Además, un aspecto clave de todo lo que venimos describiendo en este capítulo tiene que ver con el impulso tecnológico-educativo de las propias administraciones

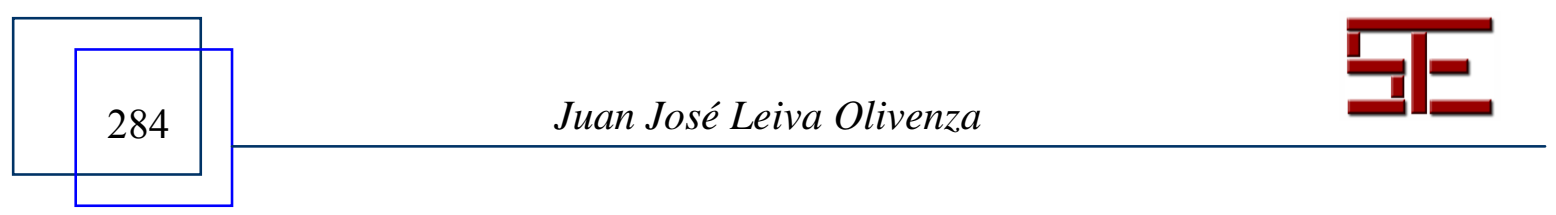




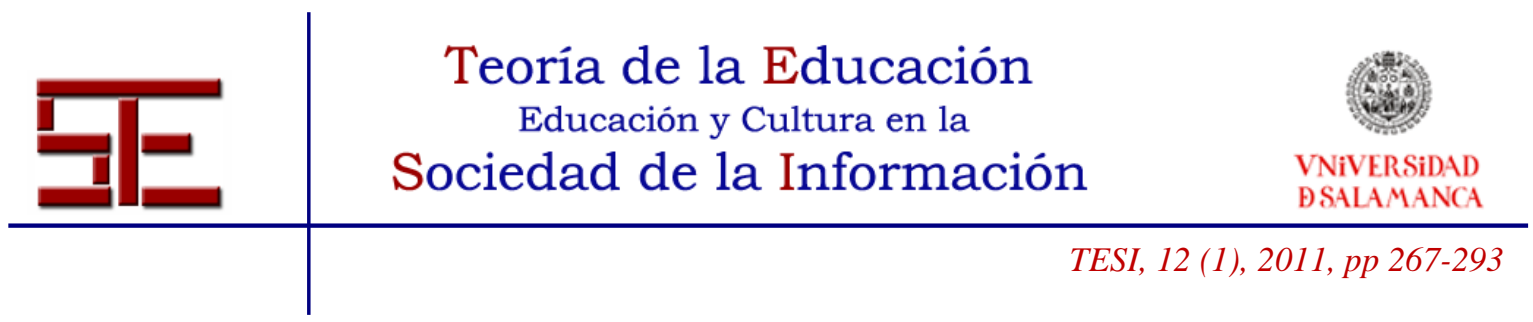

educativas de las diferentes comunidades autónomas, que a través de sus portales educativos están ofreciendo una gran cantidad y variedad de recursos didácticos con licencias CC o licencias Copyleft. En efecto, hay varias herramientas de autor o de las Consejerías de Educación, a disposición de todos los usuarios: Cuadernia, Edilim, Ardora, Jclic..., pero algunas administraciones han creado potentes plataformas para la creación y gestión de materiales multimedia interactivos y para la formación, diseño y desarrollo de iniciativas educativas de e-learning como las comunidades autónomas de Andalucía, Castilla y León, Castilla-La Mancha, Murcia, Madrid, Extremadura, así como el propio Ministerio de Educación y Ciencia a través del ITE (http://www.ite.educacion.es/).

Otro elemento importante para los docentes es que, gracias a los recursos didácticos virtuales con licencias $\mathrm{CC}$, tienen una mayor facilidad para adaptar nuevos contenidos de aprendizaje a su programación de aula y a su alumnado: agruparlos, secuenciarlos, modificarlos. También, se favorece el aprendizaje individualizado y la atención a la diversidad, elementos claves dentro de una pedagogía inclusiva y moderna. Por otro lado, cabe destacar que todas las Consejerías de Educación de las diferentes CC.AA. tienen portales telemáticos donde los docentes disponen de recursos didácticos de uso gratuito con fines educativos y con licencias CC, generados para aplicarlos en los distintos niveles formativos (especialmente en la educación primaria y educación secundaria obligatoria).

\section{LA COMPETENCIA DIGITAL COMO OBJETIVO PEDAGÓGICO}

En el marco de la política educativa impulsada por la Comisión Europea, y más concretamente de la Estrategia de Lisboa, el Parlamento Europeo y el Consejo de la Unión Europea publicaron en el año 2005 una propuesta de recomendaciones sobre las competencias clave para el aprendizaje permanente que proporciona un instrumento de referencia europeo para la puesta en práctica de programas de educación y formación que promuevan la adquisición de estas competencias. En lo referente a la competencia digital, de acuerdo a este documento se consideraba que ta competencia digital entraña el uso seguro y crítico de las tecnologías de la sociedad de la información (TSI) para el trabajo, el ocio y la comunicación. Se sustenta en las competencias básicas en materia de TSI: el uso de ordenadores para obtener, evaluar, almacenar, producir, presentar $e$ intercambiar información, y comunicarse y participar en redes de colaboración a través de Internet". En cuanto a los conocimientos, capacidades y

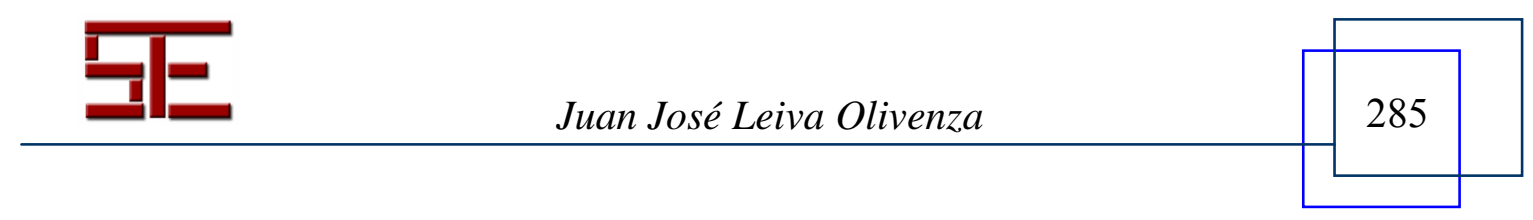




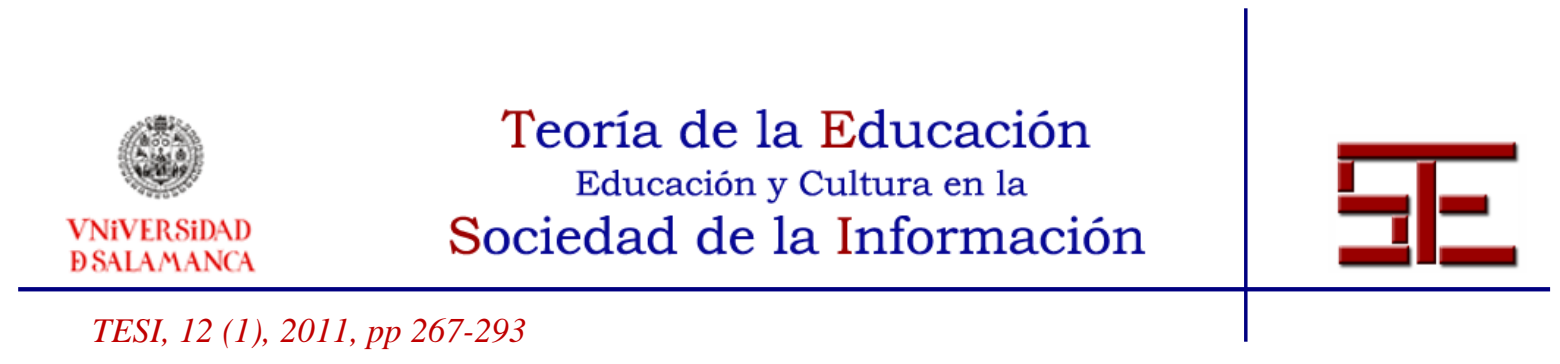

actitudes relacionados con esta competencia, el documento hace referencia a conocimientos instrumentales en el ámbito de las TIC, la capacidad de utilizar las tecnologías digitales en apoyo del pensamiento crítico, la creatividad y la innovación, además de la comprensión de las oportunidades y los riesgos potenciales que ofrecen Internet y la comunicación por medios electrónicos y el conocimiento de los principios legales y éticos por los que debe regirse el uso de estas tecnologías. Asimismo, esta competencia hace referencia al interés por participar en comunidades y redes con fines culturales, sociales o profesionales.

La adquisición de esta competencia supone adquirir las capacidades necesarias para: buscar, obtener y tratar la información; evaluar su pertinencia y utilizarla de manera crítica y sistemática; además de producir, presentar y comprender información compleja. La educación actual debe generar ambientes de enseñanza-aprendizaje apropiados para la producción y transferencia de conocimientos relevantes $\mathrm{y}$ funcionales, competencias genéricas y específicas de cada disciplina y de cada nuevo tipo de aprendizaje. Los nuevos modelos pedagógicos trasladan el protagonismo educativo hacia el estudiante como principal agente de aprendizaje. Este protagonismo hace que el estudiante tenga que gestionar su propio conocimiento y, por tanto, se debe preparar para que pueda adquirir una serie de estrategias y competencias que le permitan llevar a cabo sus estudios en la universidad de manera satisfactoria. Esto conlleva un proceso de aprendizaje centrado más en las actividades funcionales y no tanto en contenidos que no son relevantes para su futura aplicabilidad en los entornos laborales dinámicos y cambiantes del siglo XXI. Teniendo en cuenta los nuevos roles de las TIC en el aprendizaje, no podemos obviar el contexto tecnológico que nos rodea: la Web 2.0. Este concepto se define como "una segunda generación en la historia del desarrollo de tecnología Web basada en comunidades de usuarios y una gama especial de servicios, como las redes sociales, los blogs, los wikis o las folcsonomías, que fomentan la colaboración y el intercambio ágil y eficaz de información entre los usuarios de una comunidad o red social. La Web 2.0 es también llamada web social por el enfoque colaborativo y de construcción social de esta herramienta" (O'Reilly, 2005: 9).

Algunos expertos advierten que las tendencias de Internet más interesantes para la educación en línea hoy en día se relacionan con el software social y la Web 2.0 (PérezMateo y Guitert, 2009). Estos mismos autores coinciden en que las herramientas de la Web 2.0, como blogs, wikis, marcadores sociales, podcasts, etc; aumentan la colaboración, la comunicación y producción de conocimiento de manera cooperativa.

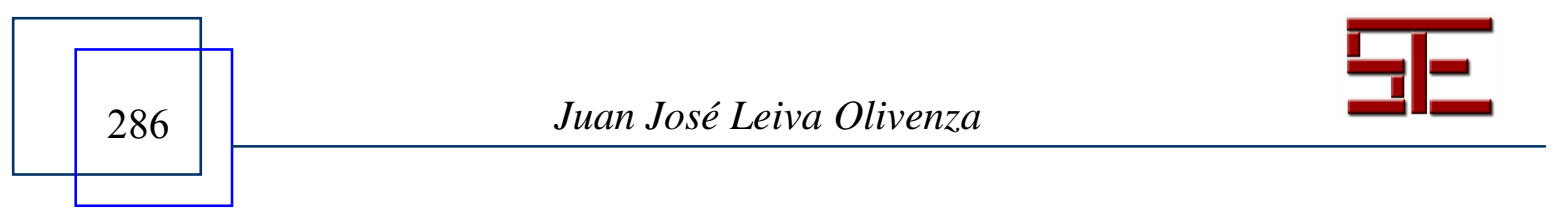




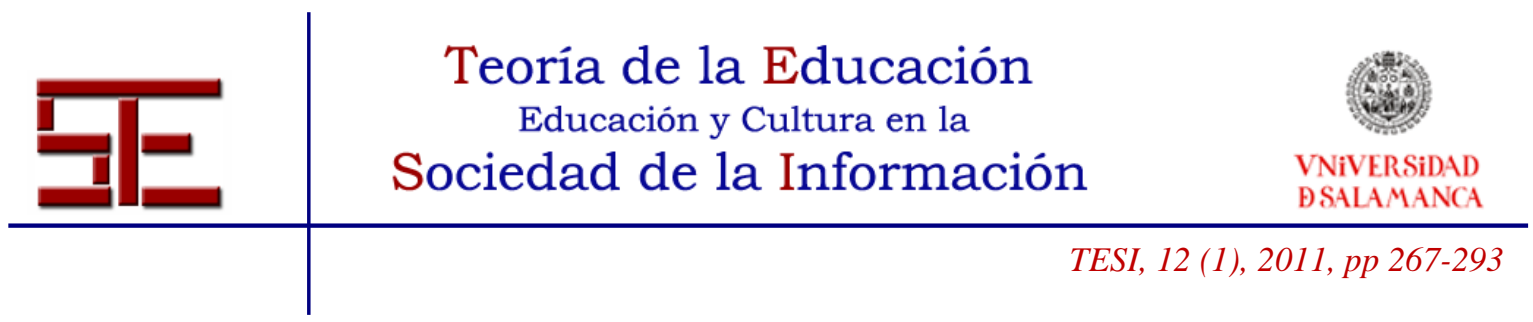

Efectivamente, una característica clave de este tipo de tecnología es la capacidad del usuario final para editar o crear información facilitada por otro usuario, favoreciendo la creación, gestión, colaboración y publicación de conocimiento. Por todo ello, resulta fundamental el papel del docente, no sólo en su rol de conocedor de las nuevas herramientas telemáticas, sino sobre todo por su habilidad didáctica por encontrar sentido y orientación educativa a todas ellas en la planificación, diseño y desarrollo de actividades escolares dirigidas a consolidar el aprendizaje de la competencia digital en los más jóvenes en una escuela conectada con el mundo de la cultura y el conocimiento.

\section{FUTURO DE LAS LICENCIAS CC}

Si tenemos en cuenta el poco tiempo desde su creación (2001), el futuro de este tipo de licencias es más que prometedor. Estamos asistiendo casi sin darnos cuenta a una emergente consolidación de un movimiento educativo y cultural que implica las licencias $\mathrm{CC}$, lo cual está contagiando a muchos profesionales de la educación interesados en consumir y crear contenidos multimedia con licencias abiertas. Por ejemplo, asistimos al nacimiento de webs dedicadas a compartir recursos de todo tipo (imágenes, vídeos, música...). Como ejemplo, en temas musicales tenemos a:

- dpop, que es una plataforma independiente para la promoción de artistas nacionales a favor de la cultura libre que así lo hacen constar licenciando sus creaciones, vinculadas al género pop, bajo alguna de las modalidades de Creative Commons u otra licencia copyleft.

- EP3.es, donde llevan desde el año 2006 apostando por la música con licencia CC. Disponen de EP3 Radio, emisora en la que sólo se emite la música que hacen los lectores y en la que no hay bandas con contrato discográfico ni temas del repertorio de la SGAE.

Por otra parte, han surgido iniciativas que aplican la filosofía y la experiencia de CC a otros ámbitos. Como ejemplo: Science Commons nació en 2005 con el objetivo de trasladar la experiencia de CC al ámbito científico. Desde su fundación intenta animar la innovación científica facilitando a investigadores, empresas y universidades el acceso a bases de datos, revistas..., así como compartir el conocimiento con los demás. También podemos encontrar revistas de divulgación que comienzan a liberar números atrasados bajo licencia CC. Por ejemplo, USERS Linux de la editorial MP Ediciones, TEC.AR, Eureka, e incluso trabajos de investigación desarrollados en universidades que tienen

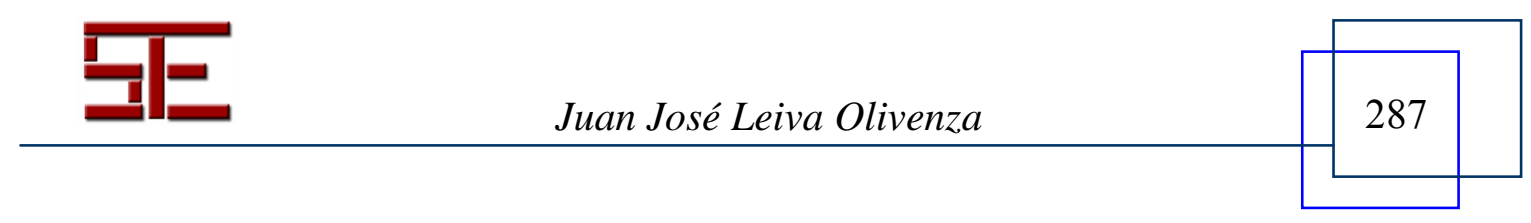




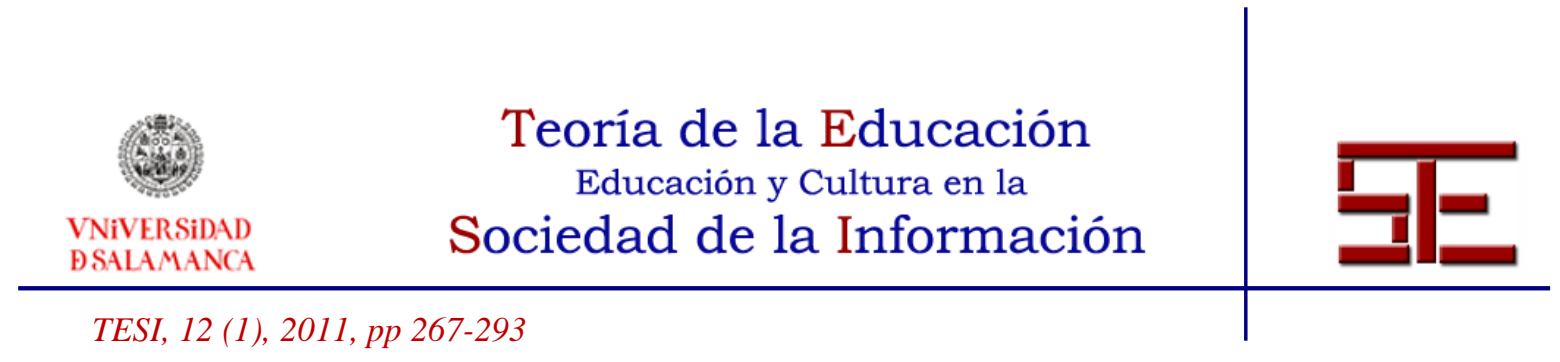

licencia CC. Muchos de los materiales multimedia en la Red pueden tener derechos de autor o copyright, en este caso no podemos usarlos públicamente sin su permiso. Pero cuando los autores desean que sus trabajos puedan ser compartidos, especialmente cuando se trata de materiales educativos, sin ánimo de lucro, se acogen a una licencia en Internet llamada Copyleft o también a las licencias $\mathrm{CC}$ donde se permite su uso siempre que se especifique quién lo ha creado, y en algunos casos que donde se emplee también tenga este tipo de licencia. Esto es lo que se conoce como materiales de uso libre, aunque siguen teniendo los autores sus derechos de autor. El futuro de las licencias CC en la educación progresa de manera imparable debido a que los avances sociales y tecnológicos hacen posible que cada vez más profesores e instituciones educativas puedan acceder, crear, modificar, publicar y distribuir diversos tipos de trabajos - obras de arte, materiales científicos y educativos, software libre, artículos- es decir, cualquier cosa que se pueda representar digitalmente y que tenga potencialidad didáctica (Vercelli, 2009). En la actualidad se están creando comunidades de aprendizaje para ejercer estas nuevas posibilidades y crear una riqueza de obras reutilizables de manera colectiva y cooperativa. Es importante concienciar al docente para que sepa qué cosas debe hacer al enseñar, por qué y para qué, así como ofrecerle un repertorio de modos de hacer (metodologías, actividades, relaciones personales y sociales, uso de materiales didácticos...), además de saber trabajar de forma individual y grupal, para obtener con ello un éxito en el proceso de enseñanza y aprendizaje de los alumnos. Es aquí donde tienen una enorme potencialidad los contenidos con licencias $\mathrm{CC}$, ya que hoy en día es necesario estimular al alumnado con una amplia e intensa diversidad de conocimientos y de materiales didácticos que sean motivadores y dinamizadores de su curiosidad e ilusión por aprender. Además es necesario trabajar con instrumentos que nos pongan en contacto directo con la gran biblioteca que es Internet, y siempre es mejor trabajar con materiales que dispongan licencias $\mathrm{CC}$ por su flexibilidad y libertad en su uso. En verdad, hoy en día, por muy detallada que sea una relación bibliográfica o de materiales didácticos para la planificación didáctica de una asignatura, siempre se necesita la aportación de fuentes y recursos didácticos de Internet, casi inagotables debido a la actual magnitud de la Red. En este punto, contar con la posibilidad de trabajar en el aula con documentos con licencias CC potencia el aprendizaje cooperativo y fomenta la motivación, no sólo del alumnado sino también de un profesorado formado en nuevos diseños formativos con TIC y en contacto con otros profesionales interesados en crear y difundir materiales didácticos de manera libre. (Sáenz, 2007).

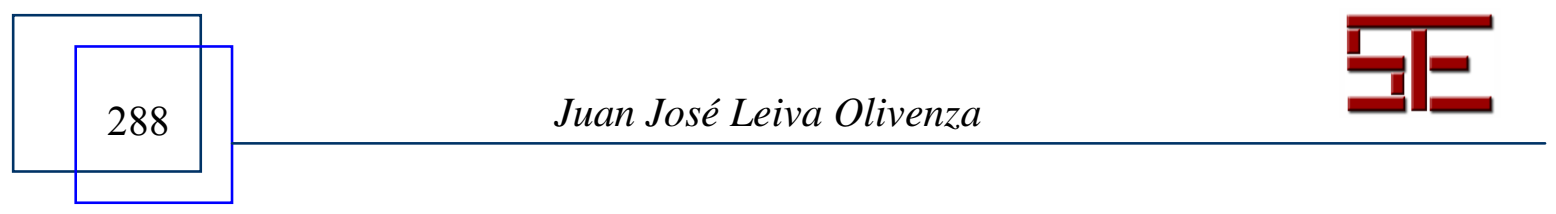




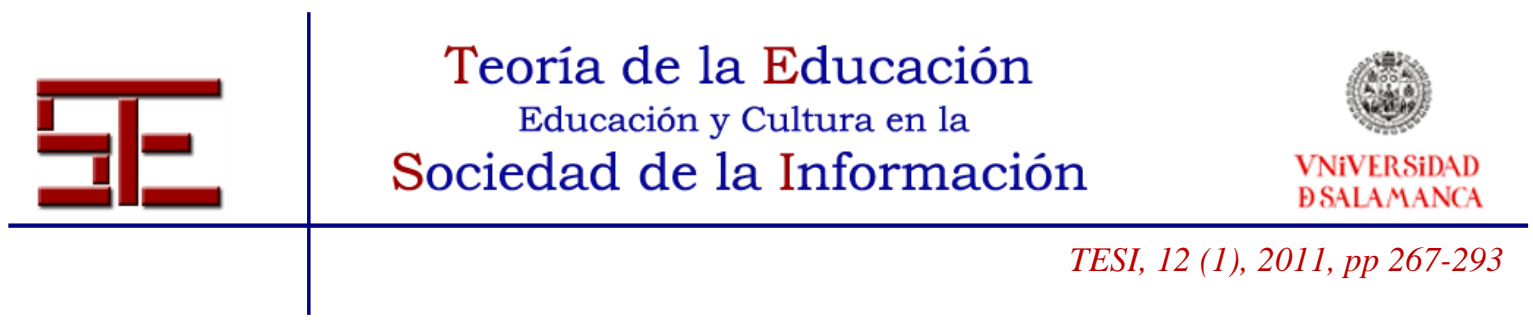

Por todo ello, y aquí adquieren una especial relevancia las licencias $\mathrm{CC}$, es donde podemos inscribir la necesidad de formar más y mejor a los profesionales de la educación. El docente no sólo se forma recibiendo cursos en los centros de profesorado, sino en multitud de lugares y de diversas maneras, como, por ejemplo: realizando reflexiones de su propia práctica, leyendo e investigando sobre educación digital, formando parte de grupos de trabajo, constituyendo comunidades de aprendizaje a través de Internet, creando materiales didácticos de manera cooperativa y con licencias CC. Es por ello que consideramos fundamental la creación de comunidades formativas de docentes en las que éstos aprenden juntos haciendo y produciendo materiales didácticos virtuales, mediante el intercambio y la coordinación pedagógica, teniendo en cuenta lo que dice el alumno y lo que aprende, lo que se hace en la Red y en clase, lo que puede aportar el descubrimiento de nuevas páginas web donde encontramos un material disponible y abierto con unas licencias que hacen de la profesión docente una auténtica oportunidad para convertirse en productores y no en meros consumidores de elearning.

\section{REFLEXIONES FINALES}

Las nuevas situaciones de aprendizaje que son necesarias para responder a las nuevas demandas sociales no implican sólo a la escuela, sino también a las familias, y como no a las instancias políticas, sociales y culturales. Hemos de poner a disposición de los más jóvenes toda la información y medios posibles de comunicación por medio de los recursos tecnológicos, y potenciar la formación en la competencia digital como un elemento fundamental de una escuela dinámica e innovadora. En este sentido, debemos subrayar el valor de la cooperación como un aspecto clave en el papel del docente como productor crítico de recursos didácticos a través de los espacios virtuales que ofrecen de manera progresiva más centros educativos. Las TIC, utilizando la interactividad que le permite al alumno, al profesorado y también a las familias poder comunicarse de manera permanente, también posibilitan el diseño y la realización de experiencias, trabajos o proyectos en común. Es más fácil trabajar juntos, aprender juntos y movilizar recursos de participación efectiva en el contexto escolar si se utilizan de manera adecuada los canales virtuales de comunicación. No nos referimos sólo a un tipo de comunicación más o menos institucional entre la organización escolar y las familias, también las familias pueden colaborar con otras familias de otros centros escolares y establecer redes de aprendizaje familiar más allá de las "fronteras" de un centro educativo determinado. Formarse a través de las redes virtuales de aprendizaje y, por tanto, compartir y utilizar recursos que han funcionado bien en determinadas áreas de

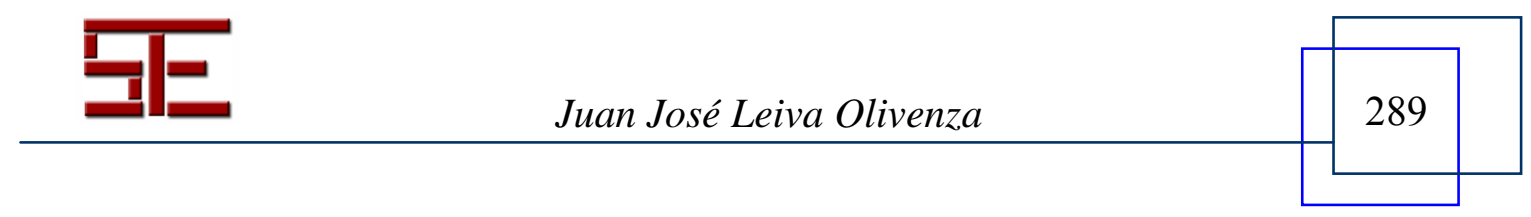




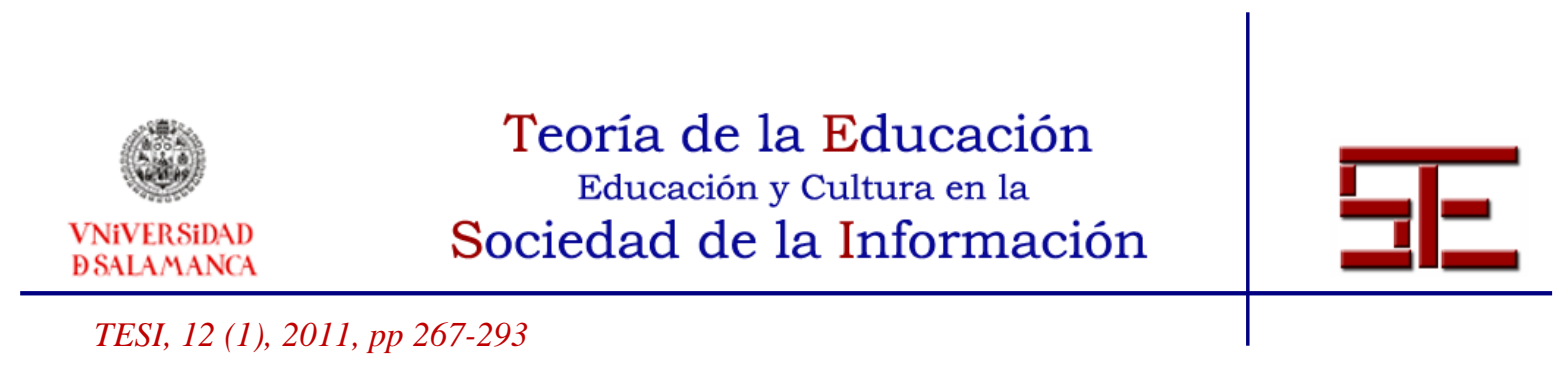

actuación educativa o programas de las que el alumnado y familias serán los principales beneficiarios. El objetivo fundamental de todo ello no es otro que promover la adquisición crítica y reflexiva de la competencia digital.

Finalmente, debemos subrayar la potencialidad de la cooperación educativa, y es que la cooperación es un valor en alza en Internet, ya que cada vez son más las comunidades de aprendizaje que emplean el e-learning para promover y difundir sus trabajos con licencias Creative Commons o con licencias completamente libres (copyleft) que posibilitan un abanico muy amplio de iniciativas educativas, sociales y comunitarias desde y en el contexto educativo. Es por ello que consideramos fundamental la creación de comunidades formativas de profesores en las que éstos aprenden juntos haciendo y produciendo materiales o dosieres educativos virtuales, mediante el intercambio y la coordinación pedagógica. Resulta fundamental que los centros escolares que vertebran su educación en la incorporación de las TIC como elemento básico de la dinámica educativa promuevan que todos los miembros de la comunidad educativa se conviertan en productores y no en meros consumidores de e-learning. Es aquí donde adquiere pleno sentido un enfoque inclusivo e integrador de las posibilidades de las TIC en los contextos educativos, incorporando experiencias y promoviendo la innovación, la cooperación y el aprendizaje interactivo.

\section{BIBLIOGRAFÍA}

Barandiarán, X. (2003). Cómo y por qué usar licencias Copyleft. http://www.etester.net/dvd/docs/es_hack02.pdf.

Cabello, F. (2005). Universidad de Barcelona-Creative Commons: Una simbiosis por la difusión del saber. En AA. VV, La universidad en la comunicación. La comunicación en la universidad. (pp. 273-279). Madrid: Edipo.

- (2006). Distorsión comunicativa: Aproximación a los modos de consumir a través de las industrias culturales en red. Málaga: Spicum.

Castillo, C. (2007). Licencias de uso Creative Commons.

En http://www.tejedoresdelweb.com/307/article-68900.html

Codina, M. (2009). Nuevos entornos de la comunicación. Indicadores sociales de la cultura del NeoRenacimiento. Revista Comunicación y Hombre, № . 5.53-65.

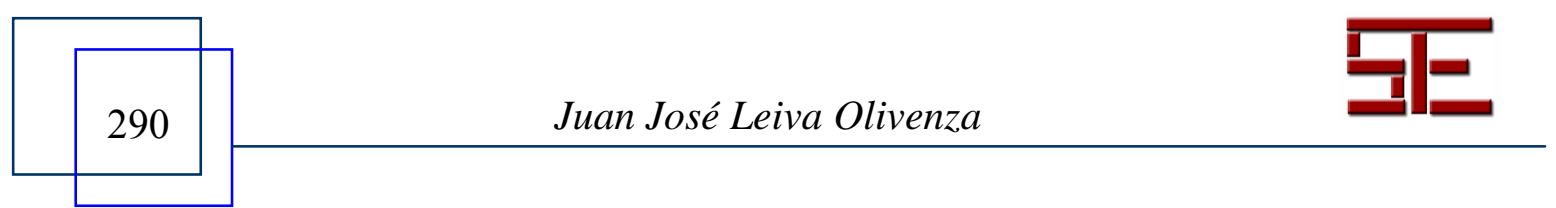




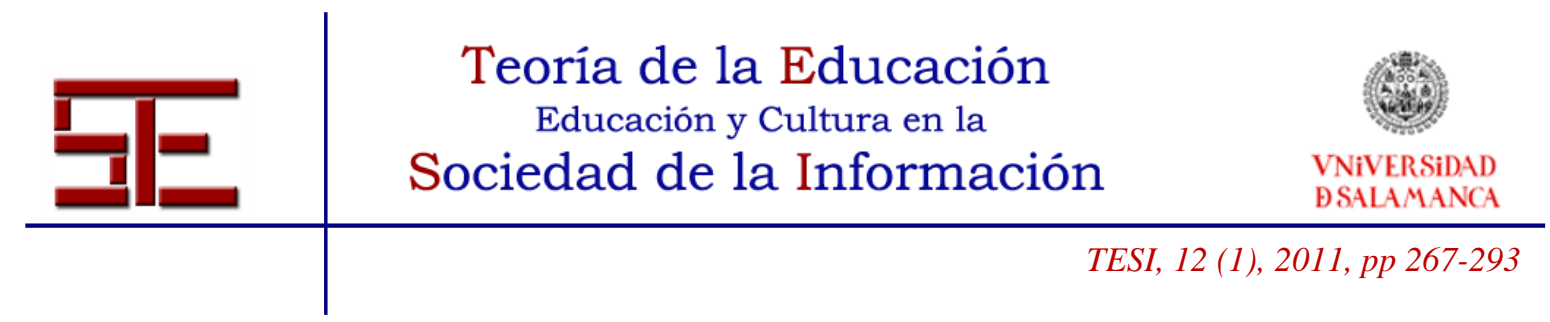

Contreras, R.S., Alpiste, F. y Eguia, J. L. (2006). Tendencias en la educación: Aprendizaje combinado. Theoria, vol 15, $\mathrm{N}^{\circ}$ 1. 11-117. Universidad del Chile.

Corsi, M. (2006). ¿Qué es la licencia Creative Commons? En

http://www.masternewmedia.org/es/2006/11/24/que_es_la_licencia_creative.htm

De La Cueva, J. (2005). Por qué las licencias Creative Commons son legales en España. En http://www.derecho-internet.org/node/272.

De Sagarra, C. (2005). Creative Commons y los derechos de autor en internet. En http://www.maestrosdelweb.com/editorial/creativecommons/.

Dulong, M. (2006). Creative Commons: licencias de contenido abierto para regular trabajos creativos. Revista Novática, 181, 28-30. En

http://www.ati.es/novatica/2006/181/181-28.pdf.

Fitzgerald, B. (2008). Copyright 2010: The Future of Copyright. European Intellectual Property Review, 43. En http://eprints.qut.edu.au/archive/00013305/.

Lessig, L. (2008). Remix: Making Art and Commerce Thrive in the Hybrid Economy.

Nueva York: Penguin Press. http://www.bloomsburyacademic.com/pdf\%20files/ Remix.pdf.

- (2009). El código: Versión 2.0. Madrid: Traficantes de sueños. http://traficantes.net/index.php/trafis/content/download/22267/218152/file/codigo $\% 202.0$ interior.pdf.

Levy, S. (1984). Hackers: Heroes of the Computer Revolution. Nueva York: Dell.

MEC (2009). Plan Escuela 2.0. En http://www.plane.gob.es/escuela-20/.

O'Reilly, T. (2005). What Is Web 2.0. Design Patterns and Business Models for the Next Generation of Software. Extraído el 15 de febrero, 2009, de http://oreilly.com/web2/archive/what-is-web-20.html.

Peláez, C. (2009). Enfoques y Estrategias Didácticas Contemporáneas Tecnologías Intervienen Activamente en los Procesos de Formación de los Individuos. En

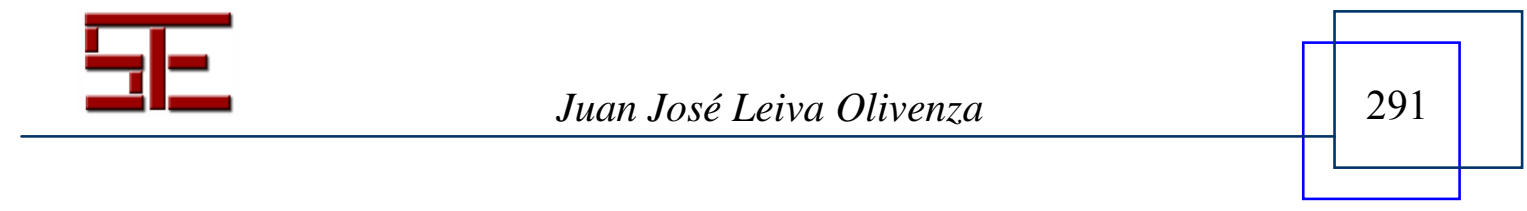




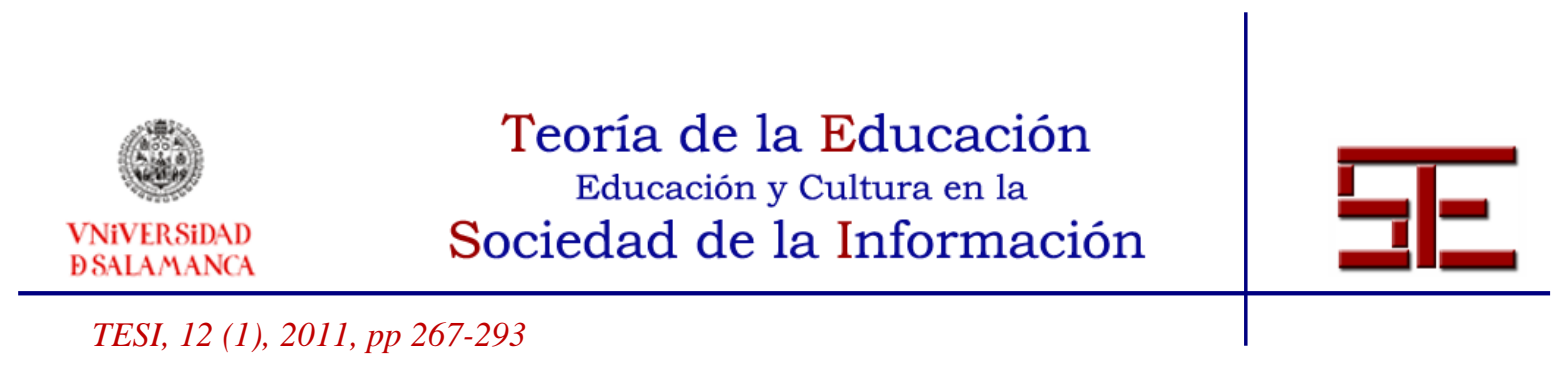

http://www.scribd.com/doc/23020047/Lastecnologias-como-una-herramienta didáctica.

Pérez-Mateo, M y Guitert. M. (2009). Herramientas para el aprendizaje colaborativo en red: el caso de la Universitat Oberta de Catalunya (UOC). Teoría de la Educación: Educación y Cultura en la Sociedad de la Información, 10 (1), 217-242.

Remmele, B. (2004). The Moral Framework of Cyberspace. Journal of Information, Communication \& Ethics in Society, 2, 125-131.

Sáenz, A. (2007). Educación y Cultura en la Sociedad de la Información. Revista Electrónica Teoría de la Educación. http://campus.usal.es/ teoriaeducacion/rev_numero_08_02/n8_02_saenzcastillo.pdf

Sánchez, J. y Ruiz, J. (2007). Mío, tuyo, nuestro. Las licencias Creative Commons. En Actas del XII Congreso Internacional de Informática Educativa. Madrid: UNED.

Stallman, R., M. (2004). Software libre para una sociedad libre. Madrid: Traficantes de Sueños. http://www.traficantes.ne t/index.php/trafis/content/ download/.

Unesco (2002). Forum on the Impact of Open Courseware for Higher Education in Developing Countries Final report. París, 1-3 julio 2002.

http://unesdoc.unesco.org/images/0012/001285/128515e.pdf.

Xalabarder, R. (2006). Las licencias Creative Commons: ¿una alternativa al copyright? Revista uocpapers, 2. http://www.uoc.edu/uocpapers/dt/esp/xalabarder.html.

Vercelli, A. (2006). Aprender la libertad: El diseño del entorno educativo y la producción colaborativa de los contenidos básicos comunes.

http://www.aprenderlalibertad.org/aprenderlalibertad.pdf.

Vercelli, A. (2009). Repensando los bienes intelectuales comunes: análisis sociotécnico sobre el proceso de construcción entre las regulaciones de derecho de autor y derecho de copia y las tecnologías digitales para su gestión. Tesis doctoral. http://www.arielvercelli.org/rlbic.pdf.

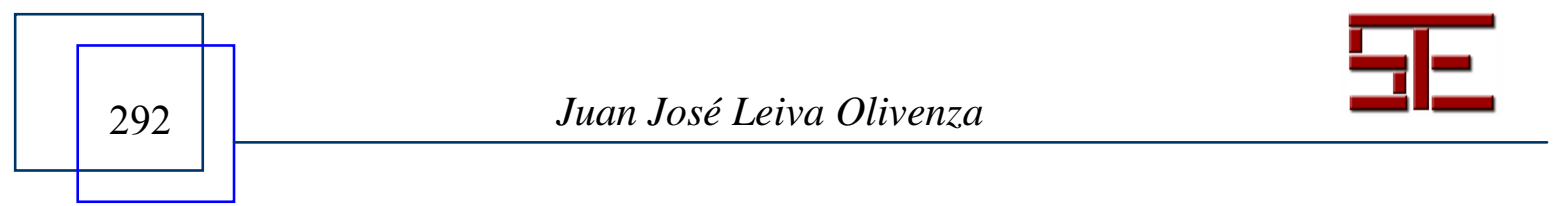




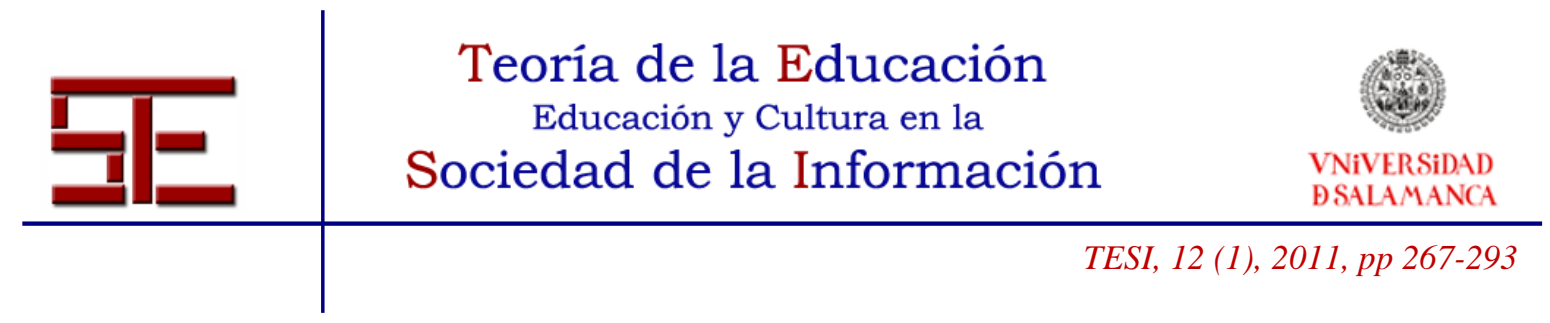

Zabalza, M. (2006). Buscando una nueva hoja de ruta en la formación. Revista de Educación, № 340, 51-58.

Para citar el presente artículo puede utilizar la siguiente referencia:

Leiva Olivenza, J. J. (2011). El docente ante las licencias creative commons: implicaciones educativas en la escuela 2.0, en Hernández Serrano, M. J. y Fuentes Agustí, M. (Coords.) La red como recurso de información en educación. Revista Teoría de la Educación: Educación y Cultura en la Sociedad de la Información. Vol. 12, n ${ }^{\circ} 1$. Universidad de Salamanca, pp. 267-293 [Fecha de consulta: dd/mm/aaaa]. http://campus.usal.es/ revistas_trabajo/index.php/revistatesi/article/view/7833/7859

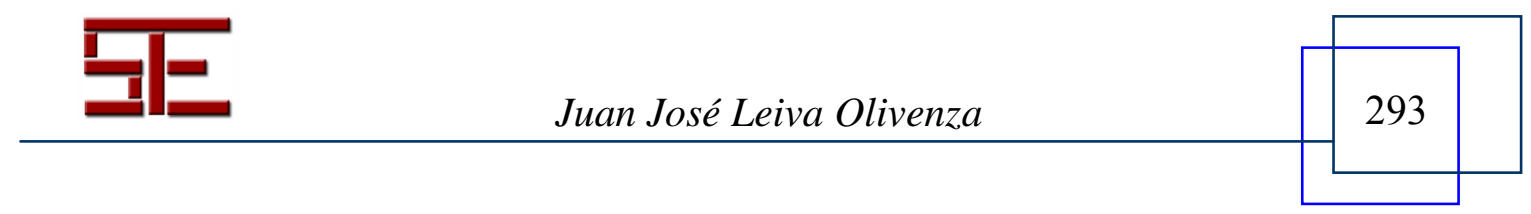

